\title{
Causal Relations Among Starch Biosynthesis, Structure, and Properties
}

\author{
Kai Wang • Robert J. Henry $•$ Robert G. Gilbert
}

Received: 11 September 2013/Revised: 1 January 2014/Accepted: 13 January 2014/Published online: 5 March 2014

(c) Springer International Publishing AG 2014

\begin{abstract}
Starch, an important carbohydrate with widespread applications in human foods, animal feeds, and many industrial products, is synthesized by plants by the action of a complex system involving many enzymes. The differing activities of these enzymes contribute to variations in starch structure among different plant species, botanical organs, and genetic backgrounds, and thus affect the physicochemical properties and end-use functions of starch. The demand for starches with particular functional properties is increasing, but the ability to produce novel starches is still limited. Starches with specific properties can potentially be produced by biotechnical modification of the starch biosynthetic pathway; however, this requires further understanding of the starch biosynthesis-structureproperties relationships. This review summarizes the state of the art in the understanding of these causal relationships: the roles of the main starch-synthesizing enzymes on starch structure, hierarchical structure of starch, advanced molecular structure characterization methods, and impact of starch structure on some functional properties. A better understanding of these relationships among starch biosynthesis, structure, and properties provides direction for genetic modification and targeted breeding programs to produce starch with desired characteristics.
\end{abstract}

\footnotetext{
K. Wang · R. G. Gilbert

Tongji School of Pharmacy, Huazhong University of Science and Technology, Wuhan 430030, Hubei, China

e-mail: k.wang3@uq.edu.au

K. Wang · R. J. Henry · R. G. Gilbert ( $₫)$

Queensland Alliance for Agriculture and Food Innovation,

The University of Queensland, Brisbane, QLD 4072, Australia

e-mail: b.gilbert@uq.edu.au

R. J. Henry

e-mail: robert.henry@uq.edu.au
}

Keywords Starch · Biosynthesis - Molecular structure · Properties $\cdot$ Enzymes

\section{Introduction}

Starch is one of the most abundant biopolymers in nature and is a main energy source component in the human diet and animal feed. It serves an energy storage function in plants and is synthesized by photosynthesis. Starch is also used for many industrial applications: papermaking, personal hygiene, renewable packaging, etc. In higher plants, starch granules are mainly found in seeds, roots, and tubers as well as in stems, leaves, fruits, and pollen.

Starch is a complex branched polymer wherein the Dglucose units are linked by $\alpha-(1 \rightarrow 4)$ linkages and the branch points are $\alpha-(1 \rightarrow 6)$ linkages (Fig. 1). It is composed of two main components. Amylose is of moderate molecular weight $\left(10^{5}-10^{6}\right)$ with a relatively small number of long chain branches, and amylopectin is a highly branched molecule with molecular weight $10^{7-9}$ and short branches. Starch structure varies among plant species, botanical organs, and genetic variations, as well as environmental effects. These structural differences are caused by alterations in the biosynthetic pathway, involving the action of multiple enzymes, including ADP-glucose pyrophosphorylase (AGPase), starch synthases (SSs), starch branching enzyme (SBE), and debranching enzyme (DBE). Various isoforms have been identified for each group of enzymes, and each isoform plays a distinct role in starch biosynthesis. Studies on genetically modified starch have been carried out to understand the function of each enzyme on starch biosynthesis [18, 53, 69]; however, the starch biosynthetic pathway is not yet fully understood, due to its complexity involving coordinated actions of multiple enzymes. 


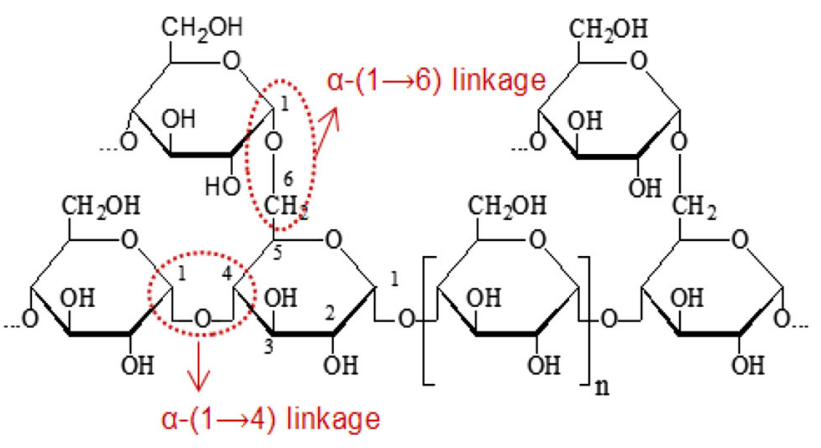

Fig. $1 \alpha-(1 \rightarrow 4)$ and $\alpha-(1 \rightarrow 6)$ linkages in starch molecules

Effects of starch biosynthetic enzymes on starch properties have been studied, and various relationships between starch biosynthesis and properties have been proposed [93, 102]; however, these relationships are indirect, as environmental factors including water, temperature, and light are also involved in starch biosynthesis. Understanding the fine structures of starch has the potential to give in-depth information on starch biosynthesis [31, 202, 204]. In addition, differences in starch structure contribute to alterations in starch properties that determine applications.

A better understanding of the relationships among the biosynthetic pathway, structure, and functional properties of starch will provide guidelines for plant breeders and geneticists to produce starch with targeted properties. Current knowledge about the role of starch-synthesizing enzymes is summarized, followed by an overview of starch hierarchical structure and molecular structure characterization methods. An advanced mathematical model that helps elucidate the enzymatic processes in starch biosynthesis, and enables effective quantification of some structural data, is briefly reviewed. We also discuss some of the main functional properties of starch, with an emphasis on the impact of starch structure on these properties.

\section{Starch Biosynthesis}

Starch is synthesized in a granular form in special organelles, the plastids. In chloroplasts, a temporary storage form is produced during photosynthesis, whereas starch for longterm storage is produced in amyloplasts [142]. Starch biosynthesis is a complex pathway controlled by at least four different types of enzymes: AGPase, SSs, SBE, and DBE. SSs can be further divided into soluble SS and granule-bound starch synthase (GBSS) (shown in Fig. 2) $[5,75,155,156]$.

The biosynthesis of amylose is mostly controlled by GBSS [111, 146] and to a lesser extent SBE, while that of amylopectin is more complex, involving the combined actions of SS, SBE, and DBE. Furthermore, the presence of the multiple isoforms of these enzymes, with each having pleiotropic effects on the other starch-synthesizing enzymes, complicates the starch biosynthetic pathway.

\section{ADP-Glucose Pyrophosphorylase}

The first key regulatory step in starch biosynthesis is the formation of adenosine $5^{\prime}$-diphosphate glucose (ADP-glucose), which is the soluble precursor and substrate for SS [63, 144]. ADP glucose is synthesized from glucose-1phosphate (Glu1P) by AGPase. The reaction scheme is:

Glu1P + ATP $\rightleftharpoons$ ADP-glucose + PPi.

In in vivo systems, the plastidial reaction is shifted in favor of ADP-glucose synthesis by converting inorganic pyrophosphate (PPi) into inorganic phosphate (Pi) [172]. As the first rate-limiting step in starch biosynthesis, much attention has been paid to modulating the activity of AGPase to increase starch yield in plants. This can be used to compensate for the yield loss associated with genotypes used to produce novel functional starches.

Both plastidial and cytosolic isoforms of AGPase have been found in cereal endosperms, meaning that AGPase activity is located in both the plastids and cytosol of cereal
Fig. 2 Overview of starch biosynthesis pathway. Main enzymes involved in starch biosynthesis are ADP-glucose pyrophosphorylase (AGPase), granule-bound starch synthase (GBSS), soluble starch synthase (SS), starch branching enzyme (SBE), and debranching enzyme (DBE), with the presence of multiple isoforms of each enzyme

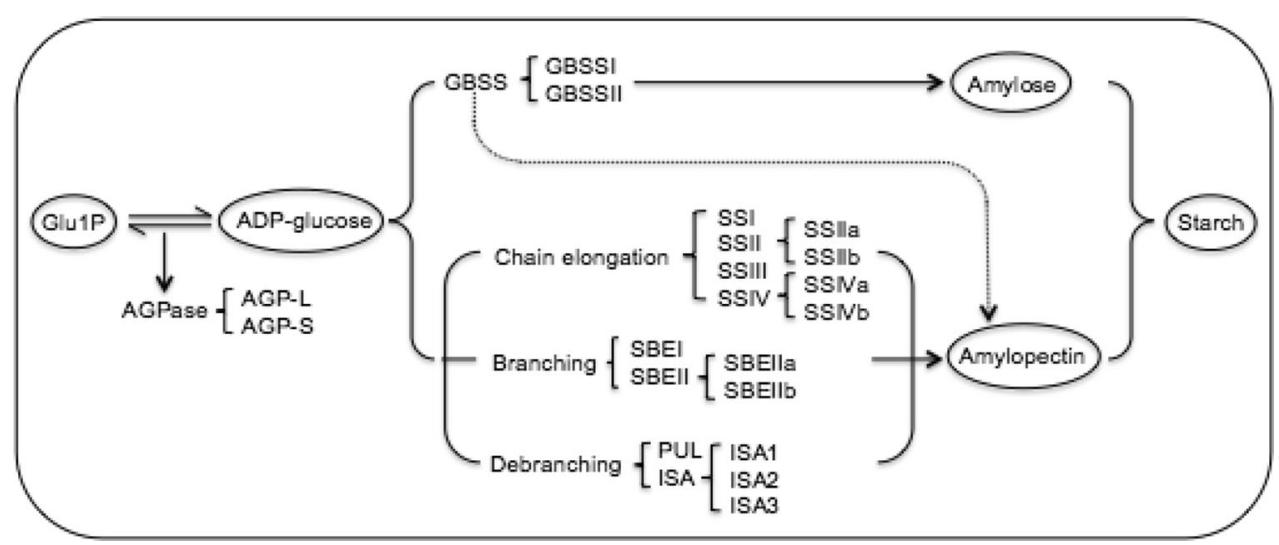


endosperms [16, 70, 89]. In the developing endosperms of maize, rice, and barley, most AGPase activity is in the cytosol with just a small portion of the total AGPase activity in the plastids [36, 153, 175].

AGPase is heterotetrameric in higher plants, consisting of two large (AGP-L) and two small (AGP-S) subunits encoded by Shrunken-2 and Brittle-2 genes, respectively [138, 139]. AGPase subunits are encoded by multiple genes. For example, in rice AGP-L is encoded by four genes: OsAGPL1, OsAGPL2, OsAGPL2, and OsAGPLA, while AGP-S is encoded by two genes: OsAGPS1 and OsAGPS2 [1]. These genes express differently in different botanical organs, which means that the composition of AGPase subunits may vary in different parts of the same plant [129, 187]. The differential expression of subunits in different organs results in varying degrees of sensitivity of AGPase to allosteric effectors. The catalytic activities of AGPase in higher plants are inhibited by $\mathrm{Pi}$ and increased by 3-phosphoglyceric acid (3-PGA) [57]. The ratio of these two allosteric effectors plays a key role in controlling starch biosynthesis. Studies on modified AGPase in maize and potato provide evidence for this phenomenon [154, 162]. In both studies, AGPase modification led to a reduced sensitivity to $\mathrm{Pi}$ inhibition, resulting in an enhanced starch yield by either increasing seed size or starch content.

\section{Starch Synthases}

Starch synthase catalyzes the transfer of a glucose unit from ADP glucose to the nonreducing end of a chain of amylose or amylopectin through the formation of a new $\alpha$ $(1 \rightarrow 4)$ glycosidic linkage. GBSS is responsible for amylose biosynthesis and is found completely within the granule matrix. SSs are mostly responsible for amylopectin biosynthesis; their distribution between granular and stromal fractions can vary among species, tissues, and developmental stages [4].

\section{Granule-Bound Starch Synthase}

There are two isoforms of GBSS, GBSSI, and GBSSII [38, $111,146]$. GBSSI, which is encoded by the waxy locus in cereals [146], is mostly confined to storage tissues, whereas GBSSII is responsible for amylose biosynthesis of transient starch in leaves and other non-storage tissues [49, 131, 189].

GBSSI elongates a growing glucan chain progressively, meaning that it does not dissociate from the glucan chain after the addition of each glucose units, but can remain associated with it to add further glucose units [37, 101]. Inhibition of GBSSI activity leads to the loss of amylose in starch of storage tissues, creating a waxy starch [99, 188]. In addition to its role in amylose biosynthesis, GBSSI is also involved in amylopectin biosynthesis, especially in forming the extra-long chain fraction [3, 35, 69]. The involvement of GBSSI in the synthesis of extra-long chains of amylopectin is supported by the fact that the reduction of GBSSI activity results in a decrease or loss of extra-long chains of amylopectin [78, 103, 116, 206].

Different opinions have been expressed regarding the impact of GBSS on starch crystalline structure. Evidence obtained in vitro [183, 195] and in vivo [12, 54, 116] suggests that GBSSI participates in the building of semicrystalline polysaccharides. For instance, in Chlamydomonas, GBSSI activity leads to the formation of a low but significant number of B-type crystallites [195]. However, Kozlov et al. [106] suggest that GBSS has no impact on the size of amylopectin clusters, the thickness of crystalline lamellae, or the structure of amylopectin defects.

In addition, starch granule shape and morphology are altered by GBSS [54, 195]. One study of potato starch has shown that in the SSIII antisense background, GBSS can have a profound influence on the structure of tuber granules, resulting in fissuring of the starch granules [54].

\section{Soluble Starch Synthase}

All known SS classes are found in the plastid stroma, and are believed to be primarily responsible for amylopectin biosynthesis [101]. Four classes of SS have been identified: SSI, SSII, SSIII, and SSIV [4, 128, 177]. There is evidence that each class has a specific role in the biosynthesis of starch, and that the activity of each class cannot be fully complemented by one or more of the remaining classes [113]. These enzyme classes appear to have different relative activities, depending on plant species and tissues, even though all appear to be ubiquitous in starch-synthesizing cells [157]. For instance, the activity of SSI is higher than that of SSIII in developing rice endosperms [51], whereas SSII and SSIII have higher activities in potato tubers [118] and pea embryos [178] than does SSI.

SSI probably plays an important role in starch biosynthesis in plants and has no known isoforms [96]. SSI is primarily responsible for synthesizing the short chains of amylopectin [34, 51, 64], with a preference for the shortest amylopectin chains as substrates [28]. Further research confirms that SSI generates short $A$ and $B_{1}$ chains (A chains carry no side branches, while $\mathrm{B}_{1}$ chains carry one or more chains without extending beyond one cluster [77, 141]), after which SSI becomes tightly bound to longer amylopectin chains and is trapped in the starch granules. Thus, further glucan chain elongation is most likely to be catalyzed by other SS enzymes [89].

The specific role of SSI in the elongation of short branches has been established in vitro as well as in vivo in 
mutants of Arabidopsis [34] and rice [51]. The amylopectin synthesized in SSI-deficient Arabidopsis leaves has a diminished proportion of branches with a degree of polymerization (DP) 8-12 and an increased proportion of branches with DP 17-20 [34]. Similar results were reported for the amylopectin in the endosperm of an SSI-deficient rice mutant. This study showed that the proportion of branches with DP 8-12 were decreased, whereas branches with DP 6-7 and DP 16-19 were increased, implying that SSI generates branches of DP 8-12 from short branches of DP 6-7, and some of the available branches of DP 8-12 are converted into longer chains by other SS enzymes (probably SSII and/or SSIII). However, the complete absence of SSI has no effect on the size and shape of seeds and starch granules or the crystallinity of endosperm starch, suggesting that other SS isoforms are capable of partly compensating for the absence of SSI function [51]. Kossmann et al. [104] reported that the reduction of potato SSI in antisense plants did not lead to detectable changes in starch structure. They suggested that this lack of change was because potato SSI was predominantly expressed in leaves and only represented a minor activity in potato tubers, where SSII and SSIII were the major isoforms expressed.

SSII plays an essential role in the synthesis of intermediate-length branches of amylopectin in cereal endosperms. Two classes of SSII genes are present in monocots: SSIIa and SSIIb. The role SSIIb plays in starch biosynthesis is unknown, as no mutants have been identified, whereas genes coding for SSIIa in storage starch tissues have been identified by mutations in multiple species, including maize, rice, wheat, barley, and pea [20, 30, 181, 205, 212]. SSIIa predominates in cereal endosperms, while SSIIb is mostly confined to photosynthetic tissues [172]. Loss of SSIIa activity results in shorter amylopectin branch chain lengths, lower starch content, reduced crystallinity, and altered granule morphology [30,121, 180]. In contrast, loss of SSII in potato causes no reduction in the starch content [42]. SSIIa appears to play a specific role in the synthesis of the intermediate-size branches with DP 12-24 by elongating short branches $[30,121,181]$; as a result, SSIIa-deficient mutants in rice show a larger proportion of short amylopectin branches ( $\mathrm{A}$ and $\mathrm{B}_{1}$ chains) and a smaller proportion of medium-size amylopectin branches, consequently leading to a lower gelatinization temperature of starch granules [181]. It has been proposed that SSIIa is responsible for the natural variation in the gelatinization temperature of starch. Umemoto et al. [182] reported three single nucleotide polymorphisms (SNPs) causing amino acid substitution of the gene that codes for SSIIa of rice, two of which are critical to the chain length distribution (CLD) of amylopectin and gelatinization properties of starch. Waters et al. [194] later confirmed the role of the two SNPs, and reported another functional SNP in exon 8. This additional SNP differentiates the tested rice samples into two groups with low and high gelatinization temperatures.

The main soluble SS isoform in tubers is SSIII, which after SSI has the second-most abundant measurable activity in maize and rice endosperms [21,51]. Two genes are responsible for the expression of SSIII in the endosperms and leaves of rice $[39,76]$. A transgenic reduction of SSIII leads to a loss of $80 \%$ of total SS activities in potato tubers and produces fissures on starch granules [42]. Loss of SSIII activity leads to alterations in starch structure and physical properties. Starches from SSIII-deficient maize and rice mutants show a decrease in long branches (DP $\geq 30$ ) as well as altered crystallinity and granule morphology [52]. It has been proposed that SSIII is responsible for the synthesis of longer amylopectin chains extending between clusters [89]. In addition, loss of SSIII in the maize endosperm may also have pleiotropic effects on other starch-synthesizing enzymes, causing decreased activity of SBEIIa [11] and an increase in other SS activities [21].

Little is known regarding the contribution of SSIV in starch biosynthesis. It has been reported that two isoforms of SSIV exist in plants: SSIVa and SSIVb, which are expressed in the endosperm and leaves, respectively [39, $112,158]$. Recently, the role for the SSIV class has been primarily shown to be in starch granule initiation in Arabidopsis, although it may also be involved in producing short branches [145]. However, no SSIV-deficient mutant has yet been characterized in cereal plants, and Arabidopsis SSIV are the only mutants so far identified [96, 145]. More identification and characterization of SSIV-deficient mutants is needed to determine the exact role of SSIV isoforms in starch biosynthesis.

In general, the inhibition of predominantly SS isoforms either singly or in combination results in only minor changes to the amylose content, although the branch CLD of amylopectin is altered dramatically [99]. Each class of SS genes appears to play a distinct role in the synthesis of amylopectin: SSI, SSIIa, and SSIII specifically contribute to synthesis of short chains, intermediate chains, and long $\mathrm{B}_{1}$ and $\mathrm{B}_{2}$ chains of amylopectin, respectively [128].

\section{Starch Branching Enzymes}

Starch branching enzyme introduces new branches on starch molecules, mainly amylopectin, by cleaving the internal $\alpha-(1 \rightarrow 4)$ glycosidic linkage of a branch chain and connecting the reducing ends of the released chains to the $\mathrm{C}_{6}$ hydroxyl groups, creating a new $\alpha-(1 \rightarrow 6)$ glycosidic linkage. SBE activity is a function of multiple isoforms, grouped into subcategories SBEI and SBEII, which have been reported to differ in terms of the length of the glucan chain transferred from in vitro studies and their substrate specificities. SBEI isoforms show higher rates of activity 
on amylose and preferentially transfer longer branches, while SBEII isoforms transfer shorter branches and show a higher activity on amylopectin [65, 66, 125, 147, 169, 173]. In some plants, the SBEII family can be further divided into SBEIIa and SBEIIb isoforms, where SBEIIb is usually specifically expressed in endosperm, and SBEIIa is present in almost every tissue. The activity of SBEIIb is higher on the amylopectin of maize than that of SBEIIa, and there are also differences in the optimum temperatures of SBEIIa and SBEIIb [65, 169]. It has been proposed that the specific function of SBEIIa might be unimportant, because no significant differences in the amylopectin structure and physicochemical properties of starch granules are found between the endosperms of wild type and SBEIIa-deficient mutants $[128,149]$. The role of SBEIIa is suggested to support, at least partially, the functions of SBEI and SBEIIb. Although the activity of SBEIIa accounts for only about $20 \%$ of the total SBE activity in the rice endosperm, it plays the predominant part in leaves, in which SBEIIb is not expressed [133].

It has been reported that the minimum chain length for the branching actions by rice and potato SBEI are DP $\sim 50$ and 40, respectively. SBEIIa and SBEIIb, however, are considered to be ineffective on synthetic amylose with a DP smaller than $\sim 100$, whereas they can attack ae-amylopectin (the amylopectin isolated from an SBEIIb-deficient rice mutant [135]) with the most abundant branches of DP around 15 [133]. SBEII isoforms form shorter chains of DP 3-12, while SBEI isoforms tend to produce short to intermediate chains ranging from DP 6 to above 30 [66, 169]. Similar results were also reported by several other groups [67, 120, 137, 147]. Recently, it has been reported that SBEI forms not only short chains of DP 6-15 with double peaks at DP 11 and DP 6 but also intermediate-size branches of DP 26-39, implying that SBEI can attack the inner region of long branches of $\mathrm{DP} \geq 41$ to produce the intermediate-size branches. On the other hand, the inner branches cannot be cleaved by SBEIIb, although SBEIIa can only partly act on the inner branches [133]. SBE only creates branches greater than a maximum DP (denoted by $\left.X_{\min }\right)$ and the branches remaining after the branching action of SBE must be more than some minimum DP (denoted by $X_{0}$ ). This means SBE only acts on chains of DP $\geq X_{\min }+X_{0}$ [202, 204]. The values of $X_{\min }$ and $X_{0}$ differ between species but they are typically 10-11 [133] and 6 [134], respectively.

\section{Starch Debranching Enzymes}

Debranching enzyme refers to the group of enzymes that hydrolyze (debranch) the $\alpha-(1 \rightarrow 6)$ glycosidic linkages of polyglucans. They probably have an important role in trimming excess branches during amylopectin biosynthesis
[126, 128]. Two classes of DBE have been identified in plants: the isoamylase-type (ISA) and the pullulanase-type (PUL, also known as limit dextrinases) [41]. ISA, of which at least three forms exist (ISA-1, ISA-2, and ISA-3), can debranch the branches of amylopectin and phytoglycogen; whereas PUL can act on the branches of pullulan and amylopectin, but not on those of phytoglycogen [128].

In the absence of ISA activities, the highly ordered structure of amylopectin is replaced by phytoglycogen or modified amylopectin [128]. Different levels of reduction in ISA activity, such as in sugaryl (sul) maize, barley, and rice mutants, result in a range of endosperm phenotypes, from a mild phenotype such as sugary amylopectin with more short chains to a more severe phenotype of phytoglycogen involving highly and randomly branched polyglucans $[15,88,107,130]$. As the result of the mutations, the physicochemical properties of starch in the grains are greatly altered. Starch from anti-ISA1 mutant shows lower viscosity and gelatinization temperature, reduced and less stable crystalline structure, and altered granule structure $[50,201]$. In addition, in order to examine the role of ISA1 in amylopectin biosynthesis in plants, Kubo et al. [108] introduced a genomic DNA fragment from a wheat ISA gene into ISA1-deficient rice mutants, and found that phytoglycogen synthesis was substantially replaced by amylopectin synthesis.

In contrast to ISA1-deficient mutants, the absence of ISA2 in a maize mutant leads to normal or near-normal kernels [109]. However, this enzyme has been reported to be involved in starch biosynthesis in leaves $[33,196]$ and potato tuber [17], and together with ISA1, they are required for activity of the ISA heteromeric enzyme [82]. The function of ISA3 in storage starch biosynthesis remains unclear, as no mutants are known to exist, while it appears to be necessary for starch degradation at night in Arabidopsis leaves [196].

Compared with ISA, the function of PUL is less understood. PUL is believed to be involved in the degradation of starch during kernel germination. However, substantial PUL activity has been detected in developing rice, maize, pea, and barley endosperms $[6,14,127,216]$. In the maize and pea endosperm, PUL has a bifunctional role, assisting in both starch biosynthesis and degradation [40, 216]. Although a PUL-deficient maize mutant shows no significant alterations in the structure and composition of the endosperm starch when compared with the wild type, a deficiency of both ISA1 and PUL leads to a significant accumulation of phytoglycogen in the endosperm-suggesting that PUL can partially compensate for the loss of ISA activity for the starch biosynthesis in cereal endosperms [40].

Two models have been proposed for the roles of DBE in amylopectin biosynthesis. One is the "glucan-trimming 
model," which is a discontinuous cycle of events involving elongation by SS, branching by SBE, selective debranching by DBE, and the formation of crystalline lamellae [126]. This model proposes that inappropriately positioned branches are removed from a precursor (termed pre-amylopectin) by DBE; the debranched structure then favors the formation of parallel double helices, leading to polysaccharide aggregation into an insoluble granular structure [5, 126]. Widely spaced branches are more likely to be cleaved by DBE than those located closer, resulting in the asymmetrical distribution of unbranched and branched areas which are required for the clusters of amylopectin branches [126]. The other model proposes that the function of DBE in starch biosynthesis is in a "clearing" role. It is assumed in this model that DBE is not directly involved in the biosynthesis of amylopectin; instead, it prevents the formation of phytoglycogen by removing soluble glucans, which are the substrates for the amylopectin biosynthetic enzymes, from the stroma. Being distinct from the "glucan-trimming model," it is proposed in this model that phytoglycogen is a separate soluble product synthesized in the stroma rather than an intermediate of amylopectin biosynthesis [172, 210].

\section{Other Starch Synthesis-Related Enzymes}

In addition to the enzymes described above, it is likely that some other enzymes are also involved in the synthesis of starch. For instance, there are other enzymes involved in starch degradation such as amylase, starch phosphorylase, and disproportionation enzyme (e.g., Denzymes). It is known that starch is degraded in the amyloplasts of cereal endosperms and in the chloroplasts of leaves; however, the roles of these degradative enzymes in starch biosynthesis, particularly in cereal endosperms, are largely unknown due to the difficulty of independently manipulating the levels of their expression in a controlled manner [211].

\section{Coordination of Enzymes}

The core enzymes described above play distinct roles in starch biosynthesis and might function separately or independently; however, starch biosynthesis is more likely to be the result of the coordinated actions of multiple enzymes. Therefore, to fully understand starch biosynthesis, the interactions between starch-synthesizing enzymes need to be assessed.

The absence of SBEIIb in the rice endosperm leads to a drop in SSI activity [135]. A study of a maize mutant showed that the loss of DBE isoforms reduced SBEIIa activity, while deficiency in ISA activity was partly compensated by PUL [40]. In Arabidopsis leaves, the activity of ISA1 can be partially fulfilled by ISA3 for starch biosynthesis [197]. It has been proposed that the coordination of SS, SBE, and DBE enzymes is accomplished by physical association of these proteins in a complex or complexes within the amyloplasts [4].

Direct evidence from biochemical analysis of plastid extracts has proven the existence of protein-protein interactions between starch-synthesizing enzymes [73, 173, 174]. Multienzyme complexes have been identified in wheat and maize endosperms. These complexes contain multiple enzymes including SS and SBE isoforms as well as some previously unknown enzymes [73]. A study of the amyloplasts in wheat endosperm has shown the existence of enzyme complexes, and suggests that the formation of these complexes is dependent on the phosphorylation status. Protein phosphorylation modifies the activities of SBE isoforms. Conversely, dephosphorylation of complex components by the addition of alkaline phosphatase can result in the disassociation of enzyme complexes [173]. Complexes found in cereal endosperms often contain SSIII that has a coiled-coil protein domain, which is thought to be responsible for protein-protein interactions [73, 105].

Apart from starch-synthesizing enzymes, some other proteins such as pyruvate orthophosphate dikinase and sucrose synthase have been detected in the complexes and may have a previously unknown role in starch biosynthesis [73]. This reveals that specific enzymes from apparently distinct metabolic pathways interact with starch-synthesizing enzymes, suggesting potential means of coordinating and regulating carbon metabolism during grain filling.

The formation of protein complexes between these enzymes is not fully understood, but it is believed that such functional associations can improve the efficiency of starch biosynthesis, as the product of one reaction becomes the substrate for another within the complex. The formation of enzyme complexes may directly alter the kinetic properties of individual components [172].

\section{Starch Structure}

Starch has complex structures, which can be described over several levels of organization (Fig. 3), ranging in scale from $\mathrm{nm}$ to $\mathrm{mm}[7,59]$. The first structural level is the individual linear branches of starch molecules linked by $\alpha$ $(1 \rightarrow 4)$ glycosidic linkages. Individual branches are joined together by $\alpha-(1 \rightarrow 6)$ glycosidic linkages at branching points to form either amylose molecules with few long branches, or the hyperbranched amylopectin molecules with a vast number of short branches; this represents the second level of structure. Level three is the cluster of double helices formed by the branches of amylopectin in native starch, arranged into alternating layers of crystalline 
Fig. 3 The complex hierarchical structure of starch

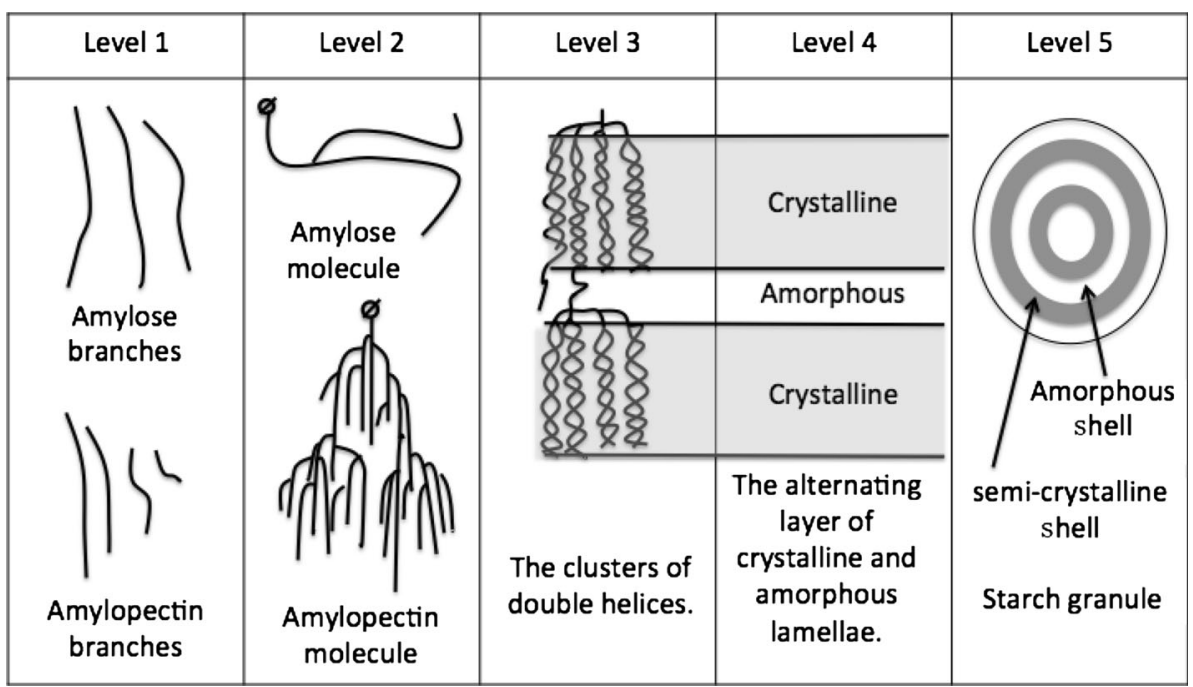

Crystalline Structure

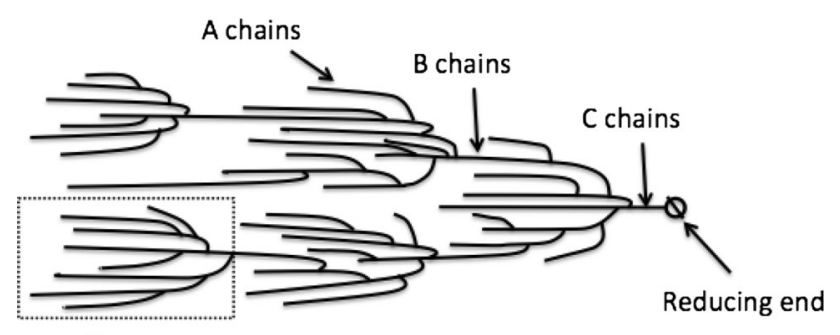

Cluster

Fig. 4 Cluster model of amylopectin structure

and amorphous lamellae (level four). These lamellae cumulatively form semicrystalline and amorphous shells or growth rings, which make up a granule (level five).

\section{Molecular Structure}

Both amylose and amylopectin have broad size and molar mass distributions. The CLD of amylose, the content of which is around $15-35 \%$ in normal starches, ranges from DP 200 to 10,000 [79, 165, 167, 168, 193]. Some amylose molecules, particularly those of large molecular weight, may have up to ten or more long branches [78].

Amylopectin branches can be divided into three distinct classes: A, B, and C chains (Fig. 4). Those without attached branches are A chains, connected through $\alpha$ $(1 \rightarrow 6)$ glycosidic linkages to the rest of the molecule. $B$ chains carry one or several other chains (A and/or B branches). Each amylopectin molecule contains a single C chain, which carries the sole reducing end group [141]. B chains confined in just one cluster are termed $\mathrm{B}_{1}$ chains, while chains spanning two, three, and four clusters are classified as $\mathrm{B}_{2}, \mathrm{~B}_{3}$, and $\mathrm{B}_{4}$ chains, respectively [77].
It is generally agreed that all except the shortest branches of amylopectin are organized into double helices, most of which then form crystalline lamellae. The branching points of amylopectin are mostly located in the amorphous lamellae, giving a semicrystalline structure to starch granules. Amylose is normally in an amorphous conformation in starch granules, and has been proven to be intertwined with amylopectin in both crystalline and amorphous lamellae. Small-angle X-ray scattering (SAXS) shows that amylopectin molecules exhibit similar repeat distance for crystalline and amorphous lamellae, which is $\sim 9 \mathrm{~nm}$, regardless of their botanical origins [190, 191]. However, there is a significant distribution of this $\sim 9 \mathrm{~nm}$ spacing in different varieties [200]. The amount of crystalline order in starch granules is generally lower than the amount of double helical order, meaning that not all double helices are involved in forming starch crystallites [29].

$\mathrm{X}$-ray diffraction (XRD) shows that starch granules can be divided into three polymorphs: A-, B-, and C-types. Amylopectin molecules in the A-type polymorphic starches, such as most cereal, tapioca, and amaranth starches, have a large number of short ( $A$ and $\left.B_{1}\right)$ branches; whereas the B-type polymorphic starches, such as potato and highamylose starches, have comparatively fewer short branches but more long branches ( $\mathrm{B}_{2}$ and longer branches) [78]. C-type polymorphic starch, such as some legume, yam, sweet potato, and lotus root starches, contains a mixture of the A- and B-type polymorphs. The differences between the A- and B-type polymorphic crystalline structures relate to the arrangement of the double helices and the relative amount of water in one unit cell. A-type polymorphic starch has monoclinic unit cells formed by the orthogonal packing of double helices with a small amount of tightly bound structural water [85]. In one unit cell, twelve 
glucopyranose units are located in two left-handed double helices packed in a parallel fashion, and four water molecules are located between the helices in each unit cell. B-type polymorphic starch is formed by a more open hexagonal packing of the double helices, with 36 water molecules per unit cell, some of which are located in the channel located in the center of the hexagonal packing [10, 84]. Amylopectin branches with different lengths differ in their preference to form a particular crystalline type. It has been proposed that chains of DP $<10$ do not crystallize, chains with a DP 10-12 tend to form an A-type crystalline structure, and chains of DP $>12$ tend to form B-type crystalline structure [72].

Witt et al. [200] recently reported that the crystallineamorphous lamellar (crystalline) structure of starch was related to the CLD (molecular structure) of starch. The proportion of short amylopectin branches is negatively correlated to the repeat distance and width distribution of the crystalline-amorphous lamellae, whereas intermediate and long amylopectin branches are positively correlated to the repeat distance and width distribution of the crystalline-amorphous lamellae.

The presence of double helices causes the starch granule to be birefringent; this can be observed using light microscopy with cross polarizers. The interference pattern observed takes the form of a Maltese cross which indicates that there is an orderly arrangement of the crystalline areas within the granule [192].

\section{Granular Structure}

Starch granules of different botanical species and different organs display different shapes and sizes [92], which can be easily identified using light or scanning electron microscopy (SEM). Starch granules display spherical, oval, disk, polygonal, elongated, kidney, and lobe shapes, with diameters varying from submicron to more than $100 \mu \mathrm{m}$ [92]. Normal and waxy maize starches are spherical and polygonal in shape. Potato starch has both oval and spherical shapes. Almost all legume starches have a characteristic bean-shaped indentation on their granules [90]. Wheat, barley, rye, and triticale starches display bimodal granule size distributions consisting of disk-shaped, large A-granules and small spherical $\mathrm{B}$-granules. The number of the A-granules is always less than that of the B-granules, but the A-granules represent the major mass of the starch [2]. Rice and oat starches exist as compound granules, which are defined as multiple granules being synthesized within a single amyloplast [95]. The compound starch granules are packed together tightly and develop into irregular polygonal shapes. Leaf starches have small, flattened granules with submicron diameters [209].
Pores or pinholes can be observed by SEM on the surfaces of some starch granules. These pores or pinholes tend to occur in clusters and are more prevalent on spherical granules of the floury endosperm $[45,81]$. Their distribution appears to be random, with varied numbers per granule. Further studies showed that these pores are openings to channels in the starch granules connecting an internal cavity from the hilum to the external surface [46], and these channels and cavities are filled with amorphous material [56]. These features may either be the site of initial enzymatic attack, or openings that allow enzymes direct access to the granule interior (hilum), or both [45]. They may also be the product of endogenous enzyme hydrolysis, as the majority of pores are close to the hilum [94].

The internal structure of a starch granule is not homogenous. The outer layer of starch granules seems to differ from the inner portion [47]. Furthermore, the surface shell of starch granules remains insoluble after cooking under low shear conditions, the remnant commonly being referred to as granule ghosts [44], showing the different compositions of the periphery of the starch granules to the inner part of the granules.

\section{Starch Molecular Structure Characterization}

Starch molecular structure can be characterized by a range of methods, principally size-exclusion chromatography (SEC, also called gel-permeation chromatography, GPC), fluorophore-assisted carbohydrate electrophoresis (FACE), "batch" multiple-angle laser light scattering (MALLS), and NMR.

\section{Size-Exclusion Chromatography}

This subject has recently been extensively reviewed [5961] so is only briefly discussed here. SEC separates by molecular size: the hydrodynamic volume $V_{\mathrm{h}}$ or the corresponding radius $R_{\mathrm{h}}$. For a complex branched polymer such as starch, there is no relation between $R_{\mathrm{h}}$ and molecular weight; for a linear polymer, such as debranched starch, there is a unique relationship. Three types of SEC detectors are commonly used: differential refractive index (DRI), which gives the weight distribution of molecules as functions of $R_{\mathrm{h}}$; viscometric, which gives the number distribution; and MALLS detection, which gives both the distribution of weight-average molecular weight, $\bar{M}_{\mathrm{w}}$, and also the $z$-average size $R_{\mathrm{g}, \mathrm{z}}$ measured by radius of gyration. The samples must be prepared in a molecularly dispersed form and without aggregation, loss, degradation, or retrogradation, which for starch is best done in a solvent and eluent comprising dimethyl sulfoxide (DMSO) and $\mathrm{LiBr}$.

In order to obtain $V_{\mathrm{h}}$ from elution time, calibration uses narrowly dispersed linear glucan standards (pullulan or 
dextran) of known molecular weights. Starch characterization by SEC suffers from band broadening, size calibration, shear scission, and low recovery of large molecules.

Although there are limitations of SEC characterization, it can still provide qualitative and semiquantitative information about the structural features of starch, especially for the fully branched amylose molecules and the chain lengths of starch molecules (especially amylose) after enzymatic debranching, as the molecules of these sizes are not significantly affected by either shear scission or the size calibration limitation.

\section{Fluorophore-Assisted Carbohydrate Electrophoresis}

Fluorophore-assisted carbohydrate electrophoresis consists of labeling the reducing end of each debranched starch chain with a fluorophore (typically 8-amino-1,3,6-pyrenetrisulfonic acid) and performing the separation of the labeled linear molecules using capillary electrophoresis with fluorescence detection, based on the different mass-tocharge ratios of linear molecules with different sizes [140].

Compared to SEC, FACE gives a more accurate CLD since it does not suffer from band broadening. However, it is limited to characterizing the branches of amylopectin (DP $\lesssim 100$ ). FACE directly gives the debranched number distribution $N_{\mathrm{de}}(X)$, while debranched data from SEC is converted from the weight distribution $w(\log X)$ to $N_{\mathrm{de}}(X)=X^{-2} w(\log X)[23]$.

\section{MALLS}

There are two types of light-scattering measurements: dynamic and static. Dynamic light scattering is based on the scattering of light by the Brownian motion of particles. In static light scattering, the intensity of scattered radiation is averaged over a relatively long time $(<2 \mathrm{~s})$ to smooth out all internal mobility [13]. With static light scattering, weight-average molar mass $\bar{M}_{\mathrm{w}}$ and $z$-average radius of gyration $R_{\mathrm{g}, \mathrm{z}}$ are obtained.

A MALLS detector uses static light scattering. Characterization of starch using an offline MALLS detector in batch mode does not involve size separation (hence avoiding the problem of shear scission), and is the best method to give (total) $\bar{M}_{\mathrm{w}}$ and $R_{\mathrm{g}, \mathrm{z}}$ for amylopectin. Since light scattering is very sensitive to large particles, it is essential to avoid the presence of aggregates and other components that are not molecularly dispersed. Neither light-scattering method can give a reliable size distribution because the signal is a complex function of the actual size distribution of the sample, and it is mathematically impossible to invert signal to distribution exactly [25].

\section{Nuclear Magnetic Resonance}

Nuclear magnetic resonance (NMR) gives the degree of branching (DB) by measuring the ratio of $\alpha-(1 \rightarrow 6)$ to $\alpha$ $(1 \rightarrow 4)$ glycosidic linkages [58]. The starch molecules must be completely dissolved, and water is unsuitable, especially for high-amylose starch samples [119]. Moreover, those starch molecules that do dissolve in water, especially the amylose ones, are ready to be retrograded due to the reassociation of these molecules with each other or with itself [207]. DMSO- $d_{6}$ has been shown to be a suitable solvent that can fully dissolve starch molecules [150]. The dissolution mechanism of starch granules in anhydrous DMSO$d_{6}$ is different from that in water. In water, the granules swell and then burst, while they do not swell but are peeled from their surface in DMSO- $d_{6}$ [124]. However, the calculation of DB from ${ }^{1} \mathrm{H}$ NMR spectra is sometimes complicated due to the presence of many different hydroxyl groups that can lead to broad signals and thus hide the other peaks. Tizzotti et al. [176] developed an improved procedure involving the use of a small amount of deuterated trifluoroacetic acid that shifts the exchangeable protons of the starch hydroxyl groups to a high frequency, contributing to clear and well-defined NMR spectra.

\section{Mathematical Model of Starch Biosynthesis}

The biosynthesis pathway of starch has not yet been fully understood. Starch structure, which is regulated by starch biosynthetic pathways, can provide in-depth information on the biosynthesis through mathematical modeling of starch biosynthesis. A simplified treatment based on general kinetic principles suggests that the debranched CLD can be plotted as $\ln N_{\mathrm{de}}(X)$ against degree of polymerization $X$, where approximately linear regions give an indication of the relative rates of chain growth and chain stoppage [22, 62, 186]. This treatment does not take into account the specific catalytic mechanism of each group of starch-synthesizing enzymes. A more advanced model has been developed by Wu et al. [202, 204].

The Wu-Gilbert model is based on three types of enzymatic processes that dominate starch structure: propagation, branching, and debranching, the activities of which are controlled by SS (or GBSS), SBE, and DBE, respectively. This model includes three important phenomena. First, SBE can only create a branch with a length longer than a certain minimum DP $\left(X_{\min }\right)$. Second, the length of moiety retained after branching must be more than a certain minimum DP $\left(X_{0}\right)$, the value of which has been reported to be approximately 6 in Arabidopsis starch. This means SBE can only operate on branches with a DP higher than $\left(X_{\min }+X_{0}\right)$. The number of monomer units at a given DP is determined by actions of several "enzyme 
isoform sets" comprising one isoform for each of a SS, SBE, and DBE.

This model gives several parameters per enzyme set: (a) $\beta$, the rate ratio of branching (catalyzed by SBE isoforms) to propagation (catalyzed by SS and GBSS); (b) $\gamma$, the ratio of debranching (modulated by DBE isoforms) to propagation; (c) the relative contribution of each enzyme isoform set; (d) $X_{\min }$; and (e) $X_{0}$. The mathematical treatment shows that $\gamma$ is not an independent variable, but is given (in a complicated way) by the values of $\beta, X_{\min }$, and $X_{0}$. Both quantitative fitting (using publicly available code [203]) and qualitative understanding of starch biosynthesis pathways can be obtained from this model. Furthermore, it can used to predict which biosynthetic pathway should be altered to produce starch with desired CLD and thus certain properties.

\section{Starch Properties}

\section{Gelatinization Properties}

Gelatinization is an order-disorder transition. When starch is heated in the presence of sufficient water, granules swell and the semicrystalline ordered structure is disrupted, leading to an amorphous structure [160, 192]. The gelatinization properties, mainly gelatinization temperature and enthalpy, are measured by differential scanning calorimetry (DSC), which reveals an endothermic event at temperatures similar to those at which structural changes of starch granules are observed [29]. The onset gelatinization temperature of starch granules reflects the heat stability of the starch crystalline regions [160], while the enthalpy of gelatinization primarily reflects the loss of molecular (double helical) order [29]. The gelatinization properties are controlled predominantly by the amylopectin CLD, starch composition, granule architecture (crystalline to amorphous ratio), and crystalline polymorphism [93].

The amylopectin CLD is a primary factor affecting starch gelatinization properties [136]. Starch crystalline structure is mainly made up of double helices of the branches of amylopectin, and the CLD of amylopectin can greatly affect the amount and the thickness of the crystallites and the defects in the crystalline lamellae. Studies on starches from various botanical origins have shown that the proportion of short amylopectin branches (DP 6-12) is negatively correlated to the gelatinization temperature $[91,132,136,151,152,184,201,208]$ and enthalpy [93]. In contrast, large proportions of intermediate (DP 13-24) and/or long amylopectin branches (DP $\geq 25$ ) can increase the gelatinization temperature and enthalpy [93, 97, 160]. These phenomena are probably because a larger proportion of intermediate and/or long amylopectin branches leads to a longer repeating distance and width distribution of the crystalline-amorphous lamellae by producing greater lengths of longer crystalline components in the crystalline lamellae, thus stabilizing crystalline lamellae toward heat gelatinization; short branches, however, cannot participate in the crystallite formation and cause defects in the crystalline structure [200]. Therefore, increased proportions of longer chains shift gelatinization to higher temperatures, while short chains decrease the gelatinization temperature.

Compared to other normal starches, potato starch, which also contains more long $\mathrm{B}_{2}, \mathrm{~B}_{3}, \ldots$ branches, has a very low gelatinization temperature. This can be explained by the fact that the amylopectin of potato starch contains a substantially higher level of phosphate monoester derivatives than most normal starches. The negative charges of the phosphate derivatives repel one another, destabilize the granular structure, and reduce the gelatinization temperature [95]. In addition, this phenomenon is also attributed to the B-type polymorph of potato starch. With the same branch chain length, this polymorph displays a lower gelatinization temperature than the A-type polymorph [198] due to the differences in their crystalline packing and water content. As stated before, A-type polymorphic starch has 4 water molecules per unit cell and is more densely packed. B-type polymorphic starch, on the other hand, is less densely packed, with 36 water molecules in one unit cell [86, 148].

With regard to the influence of amylose content on the starch gelatinization properties, studies on varieties of sweet potato, buckwheat [136], and barley starches [159] showed that amylose content had no impact on the gelatinization properties. However, a similar study on waxy, normal, and high-amylose maize starches showed that high-amylose maize starches displayed higher onset gelatinization temperatures than waxy and normal maize starches [93]. This phenomenon is not due to amylose content; instead, it is because amylopectin molecules of highamylose maize starch have larger proportion of long branches (DP > 37) than their waxy and normal counterparts. As a result, larger crystallites are formed and the stability of the crystalline lamellae is increased, which need a higher temperature to melt.

Processing conditions and particle size can also affect the gelatinization properties of starch. For example, starch isolated by a strong alkaline method shows a significantly higher gelatinization temperature than that isolated by a mild alkaline protease method [143]. A reduction in particle size also leads to a large drop in the gelatinization peak, conclusion temperature, and enthalpy [71, 117].

\section{Pasting Properties}

Pasting properties play a key role for starch applications, especially for starches used as thickening and stabilizing 
agents. The pasting properties are commonly measured using the Brabender Viscoamylograph and Rapid ViscoAnalyzer (RVA), by testing changes in the viscosity of a starch paste during a cooking and cooling cycle [32]. The data can be simplified into a series of parameters including pasting temperature, peak viscosity, final viscosity, breakdown, and setback.

The proportions of amylose and lipids are major factors associated with pasting properties. Amylopectin contributes to starch granules swelling and pasting, whereas amylose acts both as a diluent and as an inhibitor of swelling, especially in the presence of lipids. Lipids are found in most starches, and form insoluble single helical complexes with some of the amylose, and thus restrict starch granule swelling and lead to a lower peak viscosity and a substantially higher pasting temperature [159, 171]. This can explain the variations of starches from different botanical origins. Tuber and root starches, compared to cereal starches, show lower pasting temperatures and lower setback viscosities, resulting from the absence of lipids in tuber and root starches [114]. Regarding starches from the same botanical tissue, a negative correlation has been found between amylose content and peak viscosity of starch [27]. Waxy starches display lower pasting temperature and higher peak viscosity than their normal starch counterparts, because they contain mainly amylopectin; these starch granules thus can easily swell without any restriction from amylose or amylose-lipid complexes. High-amylose starches, however, are difficult to swell and thus display a very high pasting temperature and low peak viscosities, which can be attributed to their low amylopectin, high amylose, and amylose-lipid complex contents [93, 159].

Amylopectin fine structure is another key factor affecting pasting properties. Starches containing a large number of short branches are easily swollen and broken-resulting in a substantially lower pasting temperatures and viscosities, but higher breakdowns [42, 161, 201]. In contrast, the presence of extra-long branches in amylopectin raises the pasting temperature. Similar to amylose, these extra-long branches of amylopectin, which have been found in rice, maize, barley, millet, sorghum, and other plants [55, 77, $80,164,166,170]$, can form single helical complexes with lipids and intertwine with other branches to maintain the integrity of starch granules [93]. The extra-long branch chain content is positively and negatively correlated to setback and breakdown, respectively [68, 77, 87].

Starch granule size also has an impact on the pasting properties. Fortuna et al. [48] segregated potato, maize, and wheat starch granules into two fractions with large and small granular sizes, respectively, and found that starch with small granule size had larger specific surface area, leading to a higher pasting temperature, and a lower peak viscosity [48]. Similar results were observed in a study on the pasting properties of the A- and B-granules of wheat, barley, and triticale starches [2]. B-granules, with smaller granule size compared with A-granules, exhibited higher pasting temperatures and lower peak viscosities than their A-granule counterparts - attributed mainly to the high lipids content of B-granules. A-granules, on the other hand, consisting more $\mathrm{B}_{2}$ and longer amylopectin chains, displayed greater setback viscosities. These imply that the fine molecular structure and lipid content of starch play more important roles, compared with granule size, in controlling the pasting properties of starch.

\section{Digestibility}

Starch digestibility impacts on human health. Based on digestion rate, starch is classified into three groups: rapidly digestible starch (RDS), slowly digestible starch (SDS), and enzyme-resistant starch (RS) [43]. RDS is rapidly digested in small intestine, leading to a high blood glucose level, and seems to be related to some chronic diseases including cardiovascular diseases, insulin resistance, diabetes, and obesity [19]. SDS is digested slowly but completely, having the ability to maintain plasma glucose level over time; while RS is not digested in small intestine and can reach the colon, where it is fermented, producing shortchain fatty acids with benefits to colonic health [179]. SDS and RS are thought to have the potential to protect from diet-related diseases, including insulin resistance, colon cancer, and inflammatory bowel disease [74, 100, 110]. From a nutritional point of view, slowing starch digestion rate is beneficial to human health.

The digestion mechanism of granular starch is complicated, with various factors involved including the granular structure (granule size and surface pores), crystalline structure, and molecular structure of starch; these factors are usually interconnected [9, 214]. A positive correlation is generally observed between RS and amylose content [26, 122 , 217] probably because amylose intertwines with amylopectin crystallites, enhancing the integrity of the granular structure. However, low-amylose rice starch showed lower RS content than waxy rice starch, implying that, apart from amylose content, there are other factors involved in digestibility. This phenomenon can be explained by the lower crystallinity of low-amylose rice starch; thus, the granule is less intact and easy to digest. In addition, short amylopectin branches (DP 6-12) have been reported to be positively associated with the digestion rate. Less RS and more RDS were observed in granular starches with a larger proportion of short amylopectin branches than starches with a larger amount of long amylopectin branches [24, 160].

Starch is generally consumed by humans after cooking. Studies on cooked rice flour showed that SDS is negatively 
correlated to short amylopectin branches but positively correlated to intermediate and long amylopectin branches, and the opposite trends were observed for RDS [8]. Similarly, a study on cooked rice grains found that digestion rate tends to increase with the increase of the chain length of long amylose chains, and tends to decrease with the proportions of long amylose chains and long amylopectin chains [163]. These trends are not observed in cooked pure starch [24], possibly because the presence of plant cell walls and proteins in grain and flour can decrease the gelatinization degree of starch and retard starch dispersion, retaining some degree of granular structure. In addition, the lipids in grain and flour can form amylose-lipid complexes, which restricts the swelling of starch granule, whence the ability of enzymes to penetrate starch granules is inhibited and starch digestibility is decreased.

\section{Starch Biosynthesis-Structure-Properties Relationships}

The structure of starch varies considerably depending on their botanical origins, caused by differences in starch biosynthetic pathways, which is controlled by the combination and relative activities of the SS, SBE, and DBE isoforms, and, to a lesser extent, by other related enzymes [51].

Starch structure determines its functional properties, including the mechanical properties of starch-containing materials and the organoleptic and digestibility properties of starchy food. For example, amylose-free (waxy) starches gelatinize easily, yielding clear and stable pastes [215]. They can be used as stabilizer and thickener in food products and as an emulsifier for salad dressings, as well as used in paper manufacturing. High-amylose starches, on the other hand, having high gelling strength and film-forming ability, are useful for producing sweets, for keeping the coating on fried products crispy, and for reducing fat uptake of food upon cooking. High-amylose starches can also be processed as a source of RS with or without further modification, which has nutritional benefits as outlined previously [98, 213]. It reduces postprandial glycemic and insulin responses, thus reducing the risk for developing type II diabetes, obesity, and cardiovascular diseases $[115,123]$. The fermentation of RS by gut microflora can produce short-chain fatty acids, especially butyrate, which can prevent the incidence of colon cancer [185].

The alteration of starch structure by modifying the starch biosynthetic pathway and, consequently, physiochemical properties and functions, offers numerous possibilities for food and industrial materials. Novel starches with altered structures and improved properties have been produced in planta by biotechnological modification [83,
99, 121, 199]; however, there is still a considerable gap between our current capabilities and market needs. The mechanism of starch biosynthesis has not yet been totally understood because of its complexity, although remarkable advances have been achieved in recent years. In addition, obtaining reliable starch structural data without experimental artifacts is still a challenge due to the limits of the current starch characterization techniques. More efforts need to be made to explore further information about these relationships.

Acknowledgments We gratefully acknowledge Dr Jovin Hasjim, Mr Michael C. Sweedman, Mr Mitchell A. Sullivan, Dr Torsten Witt, and Ms Prudence O. Powell for useful discussions. Kai Wang thanks the University of Queensland and China Scholarship Council for her PhD scholarships.

\section{References}

1. Akihiro T, Mizuno K, Fujimura T (2005) Gene expression of ADP-glucose pyrophosphorylase and starch contents in rice cultured cells are cooperatively regulated by sucrose and ABA. Plant Cell Physiol 46(6):937-946. doi:10.1093/pcp/pci101

2. Ao ZH, Jane JL (2007) Characterization and modeling of the Aand B-granule starches of wheat, triticale, and barley. Carbohydr Polym 67(1):46-55. doi:10.1016/j.carbpol.2006.04.013

3. Baba T, Yoshii M, Kainuma K (1987) Acceptor molecule of granular-bound starch synthase from sweet-potato roots. Starch 39(2):52-56. doi:10.1002/star.19870390207

4. Ball SG, Morell MK (2003) From bacterial glycogen to starch: understanding the biogenesis of the plant starch granule. Annu Rev Plant Biol 54:207-233. doi:10.1146/annurev.arplant.54. 031902.134927

5. Ball S, Guan HP, James M, Myers A, Keeling P, Mouille G, Buleon A, Colonna P, Preiss J (1996) From glycogen to amylopectin: a model for the biogenesis of the plant starch granule. Cell 86(3):349-352. doi:10.1016/s0092-8674(00)80107-5

6. Beatty MK, Rahman A, Cao HP, Woodman W, Lee M, Myers AM, James MG (1999) Purification and molecular genetic characterization of ZPU1, a pullulanase-type starch-debranching enzyme from maize. Plant Physiol 119(1):255-266. doi:10. 1104/Pp.119.1.255

7. Bello-Perez LA, Rodriguez-Ambriz SL, Sanchez-Rivera MM, Agama-Acevedo E (2010) Starch macromolecular structure. In: Bertolini AC (ed) Starches: characterization, properties, and applications. CRC Press, Boca Raton, pp 33-58

8. Benmoussa M, Moldenhauer KAK, Hamaker BR (2007) Rice amylopectin fine structure variability affects starch digestion properties. J Agric Food Chem 55(4):1475-1479. doi:10.1021/ Jf062349x

9. Bird AR, Lopez-Rubio A, Shrestha AK, Gidley MJ (2009) Resistant starch in vitro and in vivo: factors determining yield, structure, and physiological relevance. In: Kasapis S, Norton IT, Ubbink JB (eds) Modern biopolymer science. Academic Press, San Diego, pp 449-510

10. Bogracheva TY, Wang YL, Wang TL, Hedley CL (2002) Structural studies of starches with different water contents. Biopolymers 64(5):268-281. doi:10.1002/bip.10190

11. Boyer CD, Preiss J (1981) Evidence for independent geneticcontrol of the multiple forms of maize endosperm branching 
enzymes and starch synthases. Plant Physiol 67(6):1141-1145. doi:10.1104/Pp.67.6.1141

12. Buleon A, Gallant DJ, Bouchet B, Mouille C, D'Hulst C, Kossmann J, Ball S (1997) Starches from A to C-Chlamydomonas reinhardtii as a model microbial system to investigate the biosynthesis of the plant amylopectin crystal. Plant Physiol 115(3):949-957. doi:10.1104/pp.115.3.949

13. Burchard W (1992) Static and dynamic light scattering approaches to structure determination of biopolymers. In: Harding SE, Sattelle DB, Bloomfield VA (eds) Light scattering from polymers. Royal Society of Chemistry, London, pp 3-22

14. Burton RA, Zhang XQ, Hrmova M, Fincher GB (1999) A single limit dextrinase gene is expressed both in the developing endosperm and in germinated grains of barley. Plant Physiol 119(3):859-871. doi:10.1104/pp.119.3.859

15. Burton RA, Jenner H, Carrangis L, Fahy B, Fincher GB, Hylton C, Laurie DA, Parker M, Waite D, van Wegen S, Verhoeven T, Denyer K (2002) Starch granule initiation and growth are altered in barley mutants that lack isoamylase activity. Plant $\mathrm{J}$ 31(1):97-112. doi:10.1046/j.1365-313X.2002.01339.x

16. Burton RA, Johnson PE, Beckles DM, Fincher GB, Jenner HL, Naldrett MJ, Denyer K (2002) Characterization of the genes encoding the cytosolic and plastidial forms of ADP-glucose pyrophosphorylase in wheat endosperm. Plant Physiol 130(3):1464-1475. doi:10.1104/Pp.010363

17. Bustos R, Fahy B, Hylton CM, Seale R, Nebane NM, Edwards A, Martin C, Smith AM (2004) Starch granule initiation is controlled by a heteromultimeric isoamylase in potato tubers. Proc Natl Acad Sci USA 101(7):2215-2220. doi:10.1073/pnas.0305920101

18. Butardo VM, Fitzgerald MA, Bird AR, Gidley MJ, Flanagan BM, Larroque O, Resurreccion AP, Laidlaw HKC, Jobling SA, Morell MK, Rahman S (2011) Impact of down-regulation of starch branching enzyme IIb in rice by artificial microRNA- and hairpin RNA-mediated RNA silencing. J Exp Bot 62(14):4927-4941. doi:10.1093/Jxb/Err188

19. Byrnes SE, Miller JCB, Denyer GS (1995) Amylopectin starch promotes the development of insulin-resistance in rats. J Nutr 125(6):1430-1437

20. Campbell MR, White PJ, Pollak LM (1994) Dosage effect at the surgery-2 locus on maize starch structure and function. Cereal Chem 71(5):464-468

21. Cao HP, Imparl-Radosevich J, Guan HP, Keeling PL, James MG, Myers AM (1999) Identification of the soluble starch synthase activities of maize endosperm. Plant Physiol 120(1):205-215. doi:10.1104/pp.120.1.205

22. Castro JV, Dumas C, Chiou H, Fitzgerald MA, Gilbert RG (2005) Mechanistic information from analysis of molecular weight distributions of starch. Biomacromolecules 6(4):2248-2259. doi:10. 1021/bm0500401

23. Castro JV, Ward RM, Gilbert RG, Fitzgerald MA (2005) Measurement of the molecular weight distribution of debranched starch. Biomacromolecules 6(4):2260-2270

24. Chavez-Murillo CE, Mendez-Montealvo G, Wang YJ, BelloPerez LA (2012) Starch of diverse Mexican rice cultivars: physicochemical, structural, and nutritional features. Starch 64(9):745-756. doi:10.1002/star.201200016

25. Chiou H, Fellows CM, Gilbert RG, Fitzgerald MA (2005) Study of rice starch structure by dynamic light scattering in aqueous solution. Carbohydr Polym 61:61-71

26. Chung HJ, Liu QA, Wang RL, Yin YL, Li AK (2010) Physicochemical properties and in vitro starch digestibility of cooked rice from commercially available cultivars in Canada. Cereal Chem 87(4):297-304. doi:10.1094/Cchem-87-4-0297

27. Collado LS, Mabesa RC, Corke H (1999) Genetic variation in the physical properties of sweet potato starch. J Agric Food Chem 47(10):4195-4201. doi:10.1021/jf990110t
28. Commuri PD, Keeling PL (2001) Chain-length specificities of maize starch synthase I enzyme: studies of glucan affinity and catalytic properties. Plant J 25(5):475-486. doi:10.1046/j.1365313x.2001.00955.x

29. Cooke D, Gidley MJ (1992) Loss of crystalline and molecular order during starch gelatinisation: origin of the enthalpic transition. Carbohydr Res 227:103-112. doi:10.1016/0008-6215(92)85063-6

30. Craig J, Lloyd JR, Tomlinson K, Barber L, Edwards A, Wang TL, Martin C, Hedley CL, Smith AM (1998) Mutations in the gene encoding starch synthase II profoundly alter amylopectin structure in pea embryos. Plant Cell 10(3):413-426

31. Cuevas RP, Daygon VD, Morell MK, Gilbert RG, Fitzgerald MA (2010) Using chain-length distributions to diagnose genetic diversity in starch biosynthesis. Carbohydr Polym 81(1):120 127. doi:10.1016/j.carbpol.2010.02.004

32. Deffenbaugh L, Walker C (1989) Comparison of starch pasting properties in the Brabender Viscoamylograph and the Rapid Visco-Analyzer. Cereal Chem 66(6):493-499

33. Delatte T, Trevisan M, Parker ML, Zeeman SC (2005) Arabidopsis mutants Atisa1 and Atisa2 have identical phenotypes and lack the same multimeric isoamylase, which influences the branch point distribution of amylopectin during starch synthesis. Plant J 41(6):815-830. doi:10.1111/j.1365-313X.2005.02348.x

34. Delvalle D, Dumez S, Wattebled F, Roldan I, Planchot V, Berbezy P, Colonna P, Vyas D, Chatterjee M, Ball S, Merida A, D'Hulst C (2005) Soluble starch synthase I: a major determinant for the synthesis of amylopectin in Arabidopsis thaliana leaves. Plant J 43(3):398-412. doi:10.1111/j.1365-313X.2005.02462.x

35. Denyer K, Clarke B, Hylton C, Tatge H, Smith AM (1996) The elongation of amylose and amylopectin chains in isolated starch granules. Plant J 10(6):1135-1143. doi:10.1046/j.1365-313X. 1996.10061135.x

36. Denyer K, Dunlap F, Thorbjornsen T, Keeling P, Smith AM (1996) The major form of ADP-glucose pyrophosphorylase in maize endosperm is extra-plastidial. Plant Physiol 112(2):779-785. doi:10.1104/pp.112.2.779

37. Denyer K, Waite D, Motawia S, Moller BL, Smith AM (1999) Granule-bound starch synthase I in isolated starch granules elongates malto-oligosaccharides processively. Biochem J 340:183-191. doi:10.1042/0264-6021:3400183

38. Denyer K, Johnson P, Zeeman S, Smith AM (2001) The control of amylose synthesis. J Plant Physiol 158(4):479-487. doi:10. 1078/0176-1617-00360

39. Dian WM, Jiang HW, Wu P (2005) Evolution and expression analysis of starch synthase III and IV in rice. J Exp Bot 56(412):623-632. doi:10.1093/jxb/eri065

40. Dinges JR, Colleoni C, James MG, Myers AM (2003) Mutational analysis of the pullulanase-type debranching enzyme of maize indicates multiple functions in starch metabolism. Plant Cell 15(3):666-680. doi:10.1105/tpc.007575

41. Doehlert DC, Knutson CA (1991) Two classes of starch debranching enzymes from developing maize kernels. J Plant Physiol 138(5):566-572

42. Edwards A, Fulton DC, Hylton CM, Jobling SA, Gidley M, Rossner U, Martin C, Smith AM (1999) A combined reduction in activity of starch synthases II and III of potato has novel effects on the starch of tubers. Plant J 17(3):251-261

43. Englyst HN, Kingman SM, Cummings JH (1992) Classification and measurement of nutritionally important starch fractions. Eur J Clin Nutr 46(Suppl 2):S33-S50

44. Fannon JE, Bemiller JN (1992) Structure of corn starch paste and granule remnants revealed by low-temperature scanning electron microscopy after cryopreparation. Cereal Chem 69(4):456-460

45. Fannon JE, Hauber RJ, Bemiller JN (1992) Surface pores of starch granules. Cereal Chem 69(3):284-288 
46. Fannon JE, Shull JM, Bemiller JN (1993) Interior channels of starch granules. Cereal Chem 70(5):611-613

47. Fannon JE, Gray JA, Gunawan N, Huber KC, BeMiller JN (2004) Heterogeneity of starch granules and the effect of granule channelization on starch modification. Cellulose 11(2):247-254. doi:10.1023/B:CELL.0000025399.66700.d7

48. Fortuna T, Januszewska R, Juszczak L, Kielski A, Palasinski M (2000) The influence of starch pore characteristics on pasting behaviour. Int J Food Sci Technol 35(3):285-291. doi:10.1046/j. 1365-2621.2000.00368.x

49. Fujita N, Taira T (1998) A 56-kDa protein is a novel granule-bound starch synthase existing in the pericarps, aleurone layers, and embryos of immature seed in diploid wheat (Triticum monococcum L.). Planta 207(1):125-132. doi:10.1007/s004250050464

50. Fujita N, Kubo A, Suh DS, Wong KS, Jane JL, Ozawa K, Takaiwa F, Inaba Y, Nakamura Y (2003) Antisense inhibition of isoamylase alters the structure of amylopectin and the physicochemical properties of starch in rice endosperm. Plant Cell Physiol 44(6):607-618. doi:10.1093/pcp/pcg079

51. Fujita N, Yoshida M, Asakura N, Ohdan T, Miyao A, Hirochika H, Nakamura Y (2006) Function and characterization of starch synthase I using mutants in rice. Plant Physiol 140(3):1070-1084. doi:10.1104/pp.105.071845

52. Fujita N, Yoshida M, Kondo T, Saito K, Utsumi Y, Tokunaga T, Nishi A, Satoh H, Park JH, Jane JL, Miyao A, Hirochika H, Nakamura Y (2007) Characterization of SSIIIa-deficient mutants of rice: the function of SSIIIa and pleiotropic effects by SSIIIa deficiency in the rice endosperm. Plant Physiol 144(4):2009-2023. doi:10.1104/pp.107.102533

53. Fujita N, Toyosawa Y, Utsumi Y, Higuchi T, Hanashiro I, Ikegami A, Akuzawa S, Yoshida M, Mori A, Inomata K, Itoh R, Miyao A, Hirochika H, Satoh H, Nakamura Y (2009) Characterization of pullulanase (PUL)-deficient mutants of rice (Oryza sativa L.) and the function of PUL on starch biosynthesis in the developing rice endosperm. J Exp Bot 60(3):1009-1023. doi:10. 1093/jxb/ern349

54. Fulton DC, Edwards A, Pilling E, Robinson HL, Fahy B, Seale R, Kato L, Donald AM, Geigenberger P, Martin C, Smith AM (2002) Role of granule-bound starch synthase in determination of amylopectin structure and starch granule morphology in potato. J Biol Chem 277(13):10834-10841. doi:10.1074/jbc. M111579200

55. Gaffa T, Yoshimoto Y, Hanashiro I, Honda O, Kawasaki S, Takeda Y (2004) Physicochemical properties and molecular structures of starches from millet (Pennisetum typhoides) and sorghum (Sorghum bicolor L. Moench) cultivars in Nigeria. Cereal Chem 81(2):255-260. doi:10.1094/cchem.2004.81.2.255

56. Gallant DJ, Bouchet B, Baldwin PM (1997) Microscopy of starch: evidence of a new level of granule organization. Carbohydr Polym 32(3-4):177-191. doi:10.1016/S0144-8617(97)00008-8

57. Ghosh HP, Preiss J (1966) Adenosine diphosphate glucose pyrophosphorylase a regulatory enzyme in the biosynthesis of starch in spinach leaf chloroplasts. J Biol Chem 241(19): 4491-4504

58. Gidley MJ (1985) Quantification of the structural features of starch polysaccharides by NMR-spectroscopy. Carbohydr Res 139(Jun):85-93. doi:10.1016/0008-6215(85)90009-6

59. Gilbert RG (2011) Size-separation characterization of starch and glycogen for biosynthesis-structure-property relationships. Anal Bioanal Chem 399(4):1425-1438. doi:10.1007/s00216010-4435-8

60. Gilbert RG, Witt T, Hasjim J (2013) What is being learnt about starch properties from multiple-level characterization. Cereal Chem 90(4):312-325. doi:10.1094/CCHEM-11-12-0141-FI

61. Gilbert RG, Wu AC, Sullivan MA, Sumarriva GE, Ersch N, Hasjim J (2013) Improving human health through understanding the complex structure of glucose polymers. Anal Bioanal Chem 405(28):8969-8980. doi:10.1007/s00216-00013-07129-00211

62. Gray-Weale AA, Cave RA, Gilbert RG (2009) Extracting physically useful information from multiple-detection size-separation data for starch. Biomacromolecules 10(9):2708-2713. doi:10.1021/Bm900761q

63. Greene TW, Hannah LC (1998) Adenosine diphosphate glucose pyrophosphorylase, a rate-limiting step in starch biosynthesis. Physiol Plant 103(4):574-580. doi:10.1034/j.1399-3054.1998. 1030417.x

64. Guan HP, Keeling PL (1998) Starch biosynthesis: understanding the functions and interactions of multiple isozymes of starch synthase and branching enzyme. Trends Glycosci Glycotechnol 10(54):307-319

65. Guan HP, Preiss J (1993) Differentiation of the properties of the branching isozymes from maize (Zea mays). Plant Physiol 102(4):1269-1273. doi:10.1104/pp.102.4.1269

66. Guan HP, Li P, Imparl-Radosevich J, Preiss J, Keeling P (1997) Comparing the properties of Escherichia coli branching enzyme and maize branching enzyme. Arch Biochem Biophys 342(1):92-98. doi:10.1006/abbi.1997.0115

67. Hamada S, Nozaki K, Ito H, Yoshimoto Y, Yoshida H, Hiraga S, Onodera S, Honma M, Takeda Y, Matsui H (2001) Two starchbranching-enzyme isoforms occur in different fractions of developing seeds of kidney bean. Biochem J 359(Pt 1):23-34. doi:10.1042/0264-6021:3590023

68. Han XZ, Hamaker BR (2001) Amylopectin fine structure and rice starch paste breakdown. J Cereal Sci 34(3):279-284. doi:10. $1006 /$ jcrs.2001.0374

69. Hanashiro I, Itoh K, Kuratomi Y, Yamazaki M, Igarashi T, Matsugasako JI, Takeda Y (2008) Granule-bound starch synthase $\mathrm{I}$ is responsible for biosynthesis of extra-long unit chains of amylopectin in rice. Plant Cell Physiol 49(6):925-933. doi: $10.1093 / \mathrm{pcp} / \mathrm{pcn} 066$

70. Hannah LC, James M (2008) The complexities of starch biosynthesis in cereal endosperms. Curr Opin Biotechnol 19(2):160-165. doi:10.1016/j.copbio.2008.02.013

71. Hasjim J, li E, Dhital S (2013) Milling of rice grains: effects of starch/ flour structures on gelatinization and pasting properties. Carbohydr Polym 92(1):682-690. doi:10.1016/j.carbpol.2012.09.023

72. Helbert W, Schülein M, Henrissat B (1996) Electron microscopic investigation of the diffusion of Bacillus licheniformis $\alpha$ amylase into corn starch granules. Int $\mathrm{J}$ Biol Macromol 19(3):165-169. doi:10.1016/0141-8130(96)01123-3

73. Hennen-Bierwagen TA, Lin Q, Grimaud F, Planchot V, Keeling PL, James MG, Myers AM (2009) Proteins from multiple metabolic pathways associate with starch biosynthetic enzymes in high molecular weight complexes: a model for regulation of carbon allocation in maize amyloplasts. Plant Physiol 149(3):1541-1559. doi:10.1104/pp.109.135293

74. Higgins JA, Brown IL (2013) Resistant starch: a promising dietary agent for the prevention/treatment of inflammatory bowel disease and bowel cancer. Curr Opin Gastroenterol 29(2):190-194. doi:10.1097/Mog.0b013e32835b9aa3

75. Hill H, Lee LS, Henry RJ (2012) Variation in sorghum starch synthesis genes associated with differences in starch phenotype. Food Chem 131(1):175-183

76. Hirose T, Terao T (2004) A comprehensive expression analysis of the starch synthase gene family in rice (Oryza sativa L.). Planta 220(1):9-16

77. Hizukuri S (1986) Polymodal distribution of the chain lengths of amylopectins, and its significance. Carbohydr Res 147(2): 342-347. doi:10.1016/s0008-6215(00)90643-8

78. Hizukuri S, Takeda Y, Yasuda M, Suzuki A (1981) Multibranched nature of amylose and the action of debranching enzymes. Carbohydr Res 94(2):205-213 
79. Hizukuri S, Takeda Y, Maruta N, Juliano BO (1989) Molecularstructures of rice starch. Carbohydr Res 189:227-235. doi:10. 1016/0008-6215(89)84099-6

80. Horibata T, Nakamoto M, Fuwa H, Inouchi N (2004) Structural and physicochemical characteristics of endosperm starches of rice cultivars recently bred in Japan. J Appl Glycosci 51:303-313. doi: $10.5458 /$ jag. 51.303

81. Huber KC, BeMiller JN (2000) Channels of maize and sorghum starch granules. Carbohydr Polym 41(3):269-276. doi:10.1016/ s0144-8617(99)00145-9

82. Hussain ST, Iqbal M, Mazhar M (2009) Size control synthesis of starch capped-gold nanoparticles. J Nanopart Res 11(6): 1383-1391. doi:10.1007/s11051-008-9525-6

83. Ihemere U, Arias-Garzon D, Lawrence S, Sayre R (2006) Genetic modification of cassava for enhanced starch production. Plant Biotechnol J 4(4):453-465. doi:10.1111/j.1467-7652.2006.00195.x

84. Imberty A, Perez S (1988) A revisit to the three-dimensional structure of B-type starch. Biopolymers 27(8):1205-1221. doi:10.1002/bip.360270803

85. Imberty A, Chanzy H, Perez S, Buleon A, Tran V (1988) The double-helical nature of the crystalline part of A-starch. J Mol Biol 201(2):365-378. doi:10.1016/0022-2836(88)90144-1

86. Imberty A, Buleon A, Tran V, Perez S (1991) Recent advances in knowledge of starch structure. Starch 43(10):375-384. doi:10. 1002/star.19910431002

87. Inouchi N, Hibiu H, Li T, Horibata T, Fuwa H, Itani T (2005) Structure and properties of endosperm starches from cultivated rice of Asia and other countries. J Appl Glycosci 52(3):239-246. doi:10.5458/jag. 52.239

88. James MG, Robertson DS, Myers AM (1995) Characterization of the maize gene sugary 1 , a determinant of starch composition in kernels. Plant Cell 7(4):417-429. doi:10.2307/3870080

89. James MG, Denyer K, Myers AM (2003) Starch synthesis in the cereal endosperm. Curr Opin Plant Biol 6(3):215-222

90. Jane JL (2009) Structural features of starch granules II. In: BeMiller JN, Whistler RL (eds) Starch: chemistry and technology. Academic Press, New York, pp 193-236

91. Jane JL, Shen L, Chen J, Lim S, Kasemsuwan T, Nip WK (1992) Physical and chemical studies of taro starches and flours. Cereal Chem 69(5):528-535

92. Jane JL, Kasemsuwan T, Leas S, Zobel H, Robyt JF (1994) Anthology of starch granule morphology by scanning electronmicroscopy. Starch 46(4):121-129. doi:10.1002/star.19940460 402

93. Jane JL, Chen YY, Lee LF, McPherson AE, Wong KS, Radosavljevic M, Kasemsuwan T (1999) Effects of amylopectin branch chain length and amylose content on the gelatinization and pasting properties of starch. Cereal Chem 76(5):629-637. doi:10.1094/CCHEM.1999.76.5.629

94. Jane JL, Ao ZH, Duvick SA, Wiklund M, Yoo SH, Wong K, Gardner C (2003) Structures of amylopectin and starch granules: how are they synthesized? J Appl Glycosci 50(2):167-172. doi:10.5458/jag.50.167

95. Jane JL, Maningat CC, Wongsagonsup R (2010) Starch characterization, variety and application. In: Singh BP (ed) Industrial crops and uses. CAB International, Oxfordshire, pp 207-235. doi:10.1079/9781845936167.0207

96. Jeon JS, Ryoo N, Hahn TR, Walia H, Nakamura Y (2010) Starch biosynthesis in cereal endosperm. Plant Physiol Biochem 48(6):383-392. doi:10.1016/j.plaphy.2010.03.006

97. Ji Y, Seetharaman K, Wong K, Pollak LM, Duvick S, Jane J, White PJ (2003) Thermal and structural properties of unusual starches from developmental corn lines. Carbohydr Polym 51(4):439-450. doi:10.1016/S0144-8617(02)00216-3

98. Jobling S (2004) Improving starch for food and industrial applications. Curr Opin Plant Biol 7(2):210-218
99. Jobling SA, Westcott RJ, Tayal A, Jeffcoat R, Schwall GP (2002) Production of a freeze-thaw-stable potato starch by antisense inhibition of three starch synthase genes. Nat Biotechnol 20(3):295-299. doi:10.1038/nbt0302-295

100. Johnston KL, Thomas EL, Bell JD, Frost GS, Robertson MD (2010) Resistant starch improves insulin sensitivity in metabolic syndrome. Diabet Med 27(4):391-397. doi:10.1111/j.14645491.2010.02923.x

101. Keeling PL, Myers AM (2010) Biochemistry and genetics of starch synthesis. In: Doyle MP, Klaenhammer TR (eds) Annual review of food science and technology, vol 1. Annual Reviews, Palo Alto, pp 271-303. doi:10.1146/annurev.food.102308.124214

102. Kharabian-Masouleh A, Waters DLE, Reinke RF, Ward R, Henry RJ (2012) SNP in starch biosynthesis genes associated with nutritional and functional properties of rice. Sci Rep 2:1-9. doi:10.1038/srep00557

103. Kitahara K, Hamasuna K, Nozuma K, Otani M, Hamada T, Shimada T, Fujita K, Suganuma T (2007) Physicochemical properties of amylose-free and high-amylose starches from transgenic sweetpotatoes modified by RNA interference. Carbohydr Polym 69(2):233-240. doi:10.1016/j.carbpol.2006.09.025

104. Kossmann J, Abel GJW, Springer F, Lloyd JR, Willmitzer L (1999) Cloning and functional analysis of a cDNA encoding a starch synthase from potato (Solanum tuberosum L.) that is predominantly expressed in leaf tissue. Planta 208(4):503-511. doi: $10.1007 / \mathrm{s} 004250050587$

105. Kotting O, Kossmann J, Zeeman SC, Lloyd JR (2010) Regulation of starch metabolism: the age of enlightenment? Curr Opin Plant Biol 13(3):321-329. doi:10.1016/j.pbi.2010.01.003

106. Kozlov SS, Krivandin AV, Shatalova OV, Noda T, Bertoft E, Fornal J, Yuryev VP (2007) Structure of starches extracted from near-isogenic wheat lines-part II. Molecular organization of amylopectin clusters. J Therm Anal Calorim 87(2):575-584. doi:10.1007/s10973-006-7880-z

107. Kubo A, Fujita N, Harada K, Matsuda T, Satoh H, Nakamura Y (1999) The starch-debranching enzymes isoamylase and pullulanase are both involved in amylopectin biosynthesis in rice endosperm. Plant Physiol 121(2):399-409. doi:10.1104/pp.121. 2.399

108. Kubo A, Rahman S, Utsumi Y, Li ZY, Mukai Y, Yamamoto M, Ugaki M, Harada K, Satoh H, Konik-Rose C, Morell M, Nakamura Y (2005) Complementation of sugary-1 phenotype in rice endosperm with the wheat isoamylase 1 gene in supports a direct role for isoamylase1 amylopectin biosynthesis. Plant Physiol 137(1):43-56

109. Kubo A, Colleoni C, Dinges JR, Lin QH, Lappe RR, Rivenbark JG, Meyer AJ, Ball SG, James MG, Hennen-Bierwagen TA, Myers AM (2010) Functions of heteromeric and homomeric isoamylase-type starch-debranching enzymes in developing maize endosperm. Plant Physiol 153(3):956-969. doi:10.1104/ pp.110.155259

110. Lehmann U, Robin F (2007) Slowly digestible starch-its structure and health implications: a review. Trends Food Sci Technol 18(7):346-355. doi:10.1016/j.tifs.2007.02.009

111. Leloir LF, Rongine De Fekete MA, Cardini CE (1961) Starch and oligosaccharide synthesis from uridine diphosphate glucose. J Biol Chem 236(3):636-641

112. Leterrier M, Holappa LD, Broglie KE, Beckles DM (2008) Cloning, characterisation and comparative analysis of a starch synthase IV gene in wheat: functional and evolutionary implications. BMC Plant Biol 8(1):98. doi:10.1186/1471-2229-8-98

113. Li ZY, Mouille G, Kosar-Hashemi B, Rahman S, Clarke B, Gale KR, Appels R, Morell MK (2000) The structure and expression of the wheat starch synthase III gene. Motifs in the expressed gene define the lineage of the starch synthase III gene family. Plant Physiol 123(2):613-624. doi:10.1104/pp.123.2.61 
114. Lim S, Kasemsuwan T, Jane J (1994) Characterization of phosphorus in starch by 31P-nuclear magnetic resonance spectroscopy. Cereal Chem 71(5):493-498

115. Ludwig DDS (2002) The glycemic index-physiological mechanisms relating to obesity, diabetes, and cardiovascular disease. JAMA 287(18):2414-2423. doi:10.1001/jama.287.18. 2414

116. Maddelein ML, Libessart N, Bellanger F, Delrue B, Dhulst C, Vandenkoornhuyse N, Fontaine T, Wieruszeski JM, Decq A, Ball S (1994) Toward an understanding of the biogenesis of the starch granule-determination of granule-bound and soluble starch synthase functions in amylopectin synthesis. J Biol Chem 269(40):25150-25157

117. Marshall WE (1992) Effect of degree of milling of brown rice and particle size of milled rice on starch gelatinization. Cereal Chem 69(6):632-636

118. Marshall J, Sidebottom C, Debet M, Martin C, Smith AM, Edwards A (1996) Identification of the major starch synthase in the soluble fraction of potato tubers. Plant Cell 8(7):1121-1135. doi:10.1105/tpc.8.7.1121

119. McCleary BV, Charnock SJ, Rossiter PC, O'Shea MF, Power AM, Lloyd RM (2006) Measurement of carbohydrates in grain, feed and food. J Sci Food Agric 86(11):1648-1661. doi:10.1002/ Jsfa.2497

120. Mizuno K, Kawasaki T, Shimada H, Satoh H, Kobayashi E, Okumura S, Arai Y, Baba T (1993) Alteration of the structural properties of starch components by the lack of an isoform of starch branching enzyme in rice seeds. $J$ Biol Chem 268(25):19084-19091

121. Morell MK, Kosar-Hashemi B, Cmiel M, Samuel MS, Chandler P, Rahman S, Buleon A, Batey IL, Li Z (2003) Barley sex6 mutants lack starch synthase lla activity and contain a starch with novel properties. Plant J 34(2):173-185. doi:10.1046/j. 1365-313X.2003.01712.x

122. Morita T, Ito Y, Brown IL, Ando R, Kiriyama S (2007) In vitro and in vivo digestibility of native maize starch granules varying in amylose contents. J AOAC Int 90(6):1628-1634

123. Morris KL, Zemel MB (1999) Glycemic index, cardiovascular disease, and obesity. Nutr Rev 57(9):273-276. doi:10.1111/j. 1753-4887.1999.tb01810.x

124. Mukerjea R, Mukerjea R, Robyt JF (2006) Controlled peeling of the surfaces of starch granules by gelatinization in aqueous dimethyl sulfoxide at selected temperatures. Carbohydr Res 341(6):757-765. doi:10.1016/j.carres.2006.01.025

125. Mutisya J, Sathish P, Sun CX, Andersson L, Ahlandsberg S, Baguma Y, Palmqvist S, Odhiambo B, Aman P, Jansson C (2003) Starch branching enzymes in sorghum (Sorghum bicolor) and barley (Hordeum vulgare): comparative analyses of enzyme structure and gene expression. J Plant Physiol 160(8):921-930

126. Myers AM, Morell MK, James MG, Ball SG (2000) Recent progress toward understanding biosynthesis of the amylopectin crystal. Plant Physiol 122(4):989-997. doi:10.1104/pp.122.4.989

127. Nakamura Y (1996) Some properties of starch debranching enzymes and their possible role in amylopectin biosynthesis. Plant Sci (Amsterdam, Neth) 121(1):1-18. doi:10.1016/S01689452(96)04504-9

128. Nakamura Y (2002) Towards a better understanding of the metabolic system for amylopectin biosynthesis in plants: rice endosperm as a model tissue. Plant Cell Physiol 43(7):718-725. doi:10.1093/pcp/pcf091

129. Nakamura Y, Kawaguchi K (1992) Multiple forms of ADPglucose pyrophosphorylase of rice endosperm. Physiol Plant 84(3):336-342. doi:10.1111/j.1399-3054.1992.tb04673.x

130. Nakamura Y, Umemoto T, Takahata Y, Komae K, Amano E, Satoh H (1996) Changes in structure of starch and enzyme activities affected by sugary mutations in developing rice endosperm. Possible role of starch debranching enzyme (Renzyme) in amylopectin biosynthesis. Physiol Plant 97(3): 491-498. doi:10.1034/j.1399-3054.1996.970311.x

131. Nakamura T, Vrinten P, Hayakawa K, Ikeda J (1998) Characterization of a granule-bound starch synthase isoform found in the pericarp of wheat. Plant Physiol 118(2):451-459. doi:10. 1104/pp.118.2.451

132. Nakamura Y, Sakurai A, Inaba Y, Kimura K, Iwasawa N, Nagamine T (2002) The fine structure of amylopectin in endosperm from Asian cultivated rice can be largely classified into two classes. Starch 54(3-4):117-131. doi:10.1002/1521-379X (200204)54:3/4<117:AID-STAR117>3.0.CO;2-2

133. Nakamura Y, Utsumi Y, Sawada T, Aihara S, Utsumi C, Yoshida M, Kitamura S (2010) Characterization of the reactions of starch branching enzymes from rice endosperm. Plant Cell Physiol 51(5):776-794

134. Nielsen TH, Baunsgaard L, Blennow A (2002) Intermediary glucan structures formed during starch granule biosynthesis are enriched in short side chains, a dynamic pulse labeling approach. J Biol Chem 277(23):20249-20255. doi:10.1074/jbc. M201866200

135. Nishi A, Nakamura Y, Tanaka N, Satoh H (2001) Biochemical and genetic analysis of the effects of amylose-extender mutation in rice endosperm. Plant Physiol 127(2):459-472. doi:10.1104/ pp.010127

136. Noda T, Takahata Y, Sato T, Suda I, Morishita T, Ishiguro K, Yamakawa O (1998) Relationships between chain length distribution of amylopectin and gelatinization properties within the same botanical origin for sweet potato and buckwheat. Carbohydr Polym 37(2):153-158. doi:10.1016/s0144-8617(98)00047-2

137. Nozaki K, Hamada S, Nakamori T, Ito H, Sagisaka S, Yoshida H, Takeda Y, Honma M, Matsui H (2001) Major isoforms of starch branching enzymes in premature seeds of kidney bean (Phaseolus vulgaris L.). Biosci Biotechnol Biochem 65(5): 1141-1148. doi:10.1271/bbb.65.1141

138. Okita TW (1992) Is there an alternative pathway for starch synthesis. Plant Physiol 100(2):560-564. doi:10.1104/pp.100.2.560

139. Okita TW, Nakata PA, Anderson JM, Sowokinos J, Morell M, Preiss J (1990) The subunit structure of potato tuber ADP-glucose pyrophosphorylase. Plant Physiol 93(2):785-790. doi:10. 1104/pp.93.2.785

140. O'Shea MG, Samuel MS, Konik CM, Morell MK (1998) Fluorophore-assisted carbohydrate electrophoresis (FACE) of oligosaccharides: efficiency of labelling and high-resolution separation. Carbohydr Res 307(1-2):1-12. doi:10.1016/S00086215(97)10085-4

141. Peat S, Whelan WJ, Thomas GJ (1952) Evidence of multiple branching in waxy maize starch. J Chem Soc (Nov):4546-4548

142. Perez S, Bertoft E (2010) The molecular structures of starch components and their contribution to the architecture of starch granules: a comprehensive review. Starch 62(8):389-420. doi:10.1002/star.201000013

143. Radosavljevic M, Jane J, Johnson LA (1998) Isolation of amaranth starch by diluted alkaline-protease treatment. Cereal Chem 75(2):212-216. doi:10.1094/cchem.1998.75.2.212

144. Recondo E, Leloir L (1961) Adenosine diphosphate glucose and starch synthesis. Biochem Biophys Res Commun 6(2):85-88

145. Roldan I, Wattebled F, Lucas MM, Delvalle D, Planchot V, Jimenez S, Perez R, Ball S, D'Hulst C, Merida A (2007) The phenotype of soluble starch synthase IV defective mutants of Arabidopsis thaliana suggests a novel function of elongation enzymes in the control of starch granule formation. Plant $\mathbf{J}$ 49(3):492-504. doi:10.1111/j.1365-313X.2006.02968.x

146. Rongine De Fekete MA, Leloir LF, Cardini CE (1960) Mechanism of starch biosynthesis. Nature 187(4741):918-919. doi:10.1038/187918a0 
147. Rydberg U, Andersson L, Andersson R, Aman P, Larsson H (2001) Comparison of starch branching enzyme I and II from potato. Eur J Biochem 268(23):6140-6145. doi:10.1046/j.00142956.2001.02568.x

148. Sarko A, Wu HC (1978) The crystal structures of A-, B- and C-polymorphs of amylose and starch. Starch 30(3):73-78. doi:10.1002/star.19780300302

149. Satoh H, Nishi A, Fujita N, Kubo A, Nakamura Y, Kawasaki T, Okita $\mathrm{T}$ (2003) Isolation and characterization of starch mutants in rice. J Appl Glycosci 50(2):225-230. doi:10.5458/jag.50.225

150. Schmitz S, Dona AC, Castignolles P, Gilbert RG, Gaborieau M (2009) Assessment of the extent of starch dissolution in dimethyl sulfoxide by (1)H NMR spectroscopy. Macromol Biosci 9(5):506-514. doi:10.1002/mabi.200800244

151. Shi YC, Seib PA (1992) The structure of four waxy starches related to gelatinization and retrogradation. Carbohydr Res 227:131-145. doi:10.1016/0008-6215(92)85066-9

152. Shi YC, Seib PA (1995) Fine structure of maize starches from four wx-containing genotypes of the W64A inbred line in relation to gelatinization and retrogradation. Carbohydr Polym 26(2):141-147. doi:10.1016/0144-8617(94)00059-3

153. Sikka VK, Choi SB, Kavakli IH, Sakulsingharoj C, Gupta S, Ito H, Okita TW (2001) Subcellular compartmentation and allosteric regulation of the rice endosperm ADP-glucose pyrophosphorylase. Plant Sci (Amsterdam, Neth) 161(3):461-468. doi:10.1016/S0168-9452(01)00431-9

154. Singletary GW, Banisadr R, Keeling PL (1994) Heat stress during grain filling in maize: effects on carbohydrate storage and metabolism. Aust J Plant Physiol 21(6):829-841. doi:10.1071/ PP9940829

155. Slattery CJ, Kavakli IH, Okita TW (2000) Engineering starch for increased quantity and quality. Trends Plant Sci 5(7):291-298. doi:10.1016/s1360-1385(00)01657-5

156. Smith AM (2001) The biosynthesis of starch granules. Biomacromolecules 2(2):335-341. doi:10.1021/bm000133c

157. Smith AM, Denyer K, Martin C (1997) The synthesis of the starch granule. Annu Rev Plant Physiol Plant Mol Biol 48:65-87. doi:10.1146/annurev.arplant.48.1.67

158. Smith DS, Maxwell PW, De Boer SH (2005) Comparison of several methods for the extraction of DNA from potatoes and potato-derived products. J Agric Food Chem 53(26):9848-9859. doi:10.1021/Jf051201v

159. Song Y, Jane J (2000) Characterization of barley starches of waxy, normal, and high amylose varieties. Carbohydr Polym 41(4):365-377. doi:10.1016/s0144-8617(99)00098-3

160. Srichuwong S, Sunarti TC, Mishima T, Isono N, Hisamatsu M (2005) Starches from different botanical sources I: contribution of amylopectin fine structure to thermal properties and enzyme digestibility. Carbohydr Polym 60(4):529-538. doi:10.1016/j. carbpol.2005.03.004

161. Srichuwong S, Sunarti TC, Mishima T, Isono N, Hisamatsu M (2005) Starches from different botanical sources II: contribution of starch structure to swelling and pasting properties. Carbohydr Polym 62(1):25-34. doi:10.1016/j.carbpol.2005.07.003

162. Stark DM, Timmerman KP, Barry GF, Preiss J, Kishore GM (1992) Regulation of the amount of starch in plant-tissues by ADP glucose pyrophosphorylase. Science 258(5080):287-292. doi:10.1126/science.258.5080.287

163. Syahariza ZA, Sar S, Hasjim J, Tizzotti MJ, Gilbert RG (2013) The importance of amylose and amylopectin fine structures for starch digestibility in cooked rice grains. Food Chem 136(2):742-749. doi:10.1016/j.foodchem.2012.08.053; Corrigendum 145:617-618. doi:10.1016/j.foodchem.2013.08.120

164. Takeda Y, Preiss J (1993) Structures of B90 (sugary) and W64A (normal) maize starches. Carbohydr Res 240:265-275. doi:10. 1016/0008-6215(93)84189-d
165. Takeda Y, Hizukuri S, Juliano BO (1986) Purification and structure of amylose from rice starch. Carbohydr Res 148(2):299-308. doi:10.1016/S0008-6215(00)90397-5

166. Takeda Y, Hizukuri S, Juliano BO (1987) Structures of rice amylopectins with low and high affinities for iodine. Carbohydr Res 168(1):79-88. doi:10.1016/0008-6215(87)80008-3

167. Takeda Y, Maruta N, Hizukuri S (1992) Examination of the structure of amylose by tritium labeling of the reducing terminal. Carbohydr Res 227:113-120. doi:10.1016/0008-6215(92)85064-7

168. Takeda Y, Maruta N, Hizukuri S (1992) Structures of amylose subfractions with different molecular sizes. Carbohydr Res 226(2):279-285. doi:10.1016/0008-6215(92)84076-5

169. Takeda Y, Guan HP, Preiss J (1993) Branching of amylose by the branching isoenzymes of maize endosperm. Carbohydr Res 240:253-263. doi:10.1016/0008-6215(93)84188-C

170. Takeda Y, Takeda C, Mizukami H, Hanashiro I (1999) Structures of large, medium and small starch granules of barley grain. Carbohydr Polym 38(2):109-114. doi:10.1016/s0144-8617(98) 00105-2

171. Tester RF, Morrison WR (1990) Swelling and gelatinization of cereal starches. 2. Waxy rice starches. Cereal Chem 67(6):558-563

172. Tetlow IJ (2011) Starch biosynthesis in developing seeds. Seed Sci Res 21(1):5-32. doi:10.1017/S0960258510000292

173. Tetlow IJ, Wait R, Lu ZX, Akkasaeng R, Bowsher CG, Esposito S, Kosar-Hashemi B, Morell MK, Emes MJ (2004) Protein phosphorylation in amyloplasts regulates starch branching enzyme activity and protein-protein interactions. Plant Cell 16(3):694-708. doi:10.1105/tpc.017400

174. Tetlow IJ, Beisel KG, Cameron S, Makhmoudova A, Liu F, Bresolin NS, Wait R, Morell MK, Emes MJ (2008) Analysis of protein complexes in wheat amyloplasts reveals functional interactions among starch biosynthetic enzymes. Plant Physiol 146(4):1878-1891. doi:10.1104/pp.108.116244

175. Thorbjornsen T, Villand P, Denyer K, Olsen OA, Smith AM (1996) Distinct isoforms of ADP-glucose pyrophosphorylase occur inside and outside the amyloplasts in barley endosperm. Plant $\mathrm{J}$ 10(2):243-250. doi:10.1046/j.1365-313X.1996.10020243.x

176. Tizzotti MJ, Sweedman MC, Tang D, Schaefer C, Gilbert RG (2011) New 1H NMR procedure for the characterization of native and modified food-grade starches. J Agric Food Chem 59(13):6913-6919. doi:10.1021/jf201209z

177. Tomlinson K, Denyer K (2003) Starch synthesis in cereal grains. In: Callow JA (ed) Advances in botanical research, vol 40. Academic Press, San Diego, pp 1-61. doi:10.1016/s0065-2296 (05)40001-4

178. Tomlinson K, Craig J, Smith AM (1998) Differences in isoform composition of starch synthase between leaves and embryos of pea (Pisum sativum L.). Planta 204(1):86-92. doi:10.1007/s0042 50050233

179. Topping DL, Clifton PM (2001) Short-chain fatty acids and human colonic function: roles of resistant starch and nonstarch polysaccharides. Physiol Rev 81(3):1031-1064

180. Turner NA, Walker JH, Ball SG, Vaughan PFT (1996) Downregulation or long-term inhibition of protein kinase $\mathrm{C}(\mathrm{PKC})$ reduces noradrenaline release evoked via either PKC-dependent or PKC-independent pathways in human SH-SY5Y neuroblastoma cells. Neurosci Lett 220(1):37-40. doi:10.1016/S03043940(96)13245-6

181. Umemoto T, Yano M, Satoh H, Shomura A, Nakamura Y (2002) Mapping of a gene responsible for the difference in amylopectin structure between japonica-type and indica-type rice varieties. Theor Appl Genet 104(1):1-8. doi:10.1007/s001220200000

182. Umemoto T, Aoki N, Lin HX, Nakamura Y, Inouchi N, Sato Y, Yano M, Hirabayashi H, Maruyama S (2004) Natural variation in rice starch synthase IIa affects enzyme and starch properties. Funct Plant Biol 31(7):671-684. doi:10.1071/FP04009 
183. van de Wal M, D'Hulst C, Vincken JP, Buleon A, Visser R, Ball $S$ (1998) Amylose is synthesized in vitro by extension of and cleavage from amylopectin. J Biol Chem 273(35):22232-22240. doi:10.1074/jbc.273.35.22232

184. Vandeputte GE, Vermeylen R, Geeroms J, Delcour JA (2003) Rice starches. I. Structural aspects provide insight into crystallinity characteristics and gelatinisation behaviour of granular starch. J Cereal Sci 38(1):43-52. doi:10.1016/S0733-5210(02)00140-6

185. Vanmunster IP, Tangerman A, Nagengast FM (1994) Effect of resistant starch on colonic fermentation, bile-acid metabolism, and mucosal proliferation. Dig Dis Sci 39(4):834-842. doi:10. 1007/BF02087431

186. Vilaplana F, Gilbert RG (2010) Two-dimensional size/branch length distributions of a branched polymer. Macromolecules 43(17):7321-7329. doi:10.1021/Ma101349t

187. Villand P, Aalen R, Olsen O-A, Lüthi E, Lönneborg A, Kleczkowski LA (1992) PCR amplification and sequences of cDNA clones for the small and large subunits of ADP-glucose pyrophosphorylase from barley tissues. Plant Mol Biol 19(3): 381-389. doi:10.1007/BF00023385

188. Visser RGF, Somhorst I, Kuipers GJ, Ruys NJ, Feenstra WJ, Jacobsen E (1991) Inhibition of the expression of the gene for granule-bound starch synthase in potato by antisense constructs. Mol Gen Genet 225(2):289-296. doi:10.1007/BF00269861

189. Vrinten PL, Nakamura T (2000) Wheat granule-bound starch synthase I and II are encoded by separate genes that are expressed in different tissues. Plant Physiol 122(1):255-263. doi:10.1104/pp.122.1.255

190. Waigh TA, Hopkinson I, Donald AM, Butler MF, Heidelbach F, Riekel C (1997) Analysis of the native structure of starch granules with X-ray microfocus diffraction. Macromolecules 30(13):3813-3820. doi:10.1021/ma970075w

191. Waigh TA, Donald AM, Heidelbach F, Riekel C, Gidley MJ (1999) Analysis of the native structure of starch granules with small angle X-ray microfocus scattering. Biopolymers 49(1):91-105. doi:10. 1002/(sici)1097-0282(199901)49:1<91:aid-bip9>3.0.co;2-9

192. Wang TL, Bogracheva TY, Hedley CL (1998) Starch: as simple as A, B, C? J Exp Bot 49(320):481-502. doi:10.1093/jexbot/49. 320.481

193. Ward RM, Gao QY, de Bruyn H, Gilbert RG, Fitzgerald MA (2006) Improved methods for the structural analysis of the amylose-rich fraction from rice flour. Biomacromolecules 7(3):866-876. doi:10.1021/bm050617e

194. Waters DLE, Henry RJ, Reinke RF, Fitzgerald MA (2006) Gelatinization temperature of rice explained by polymorphisms in starch synthase. Plant Biotechnol J 4(1):115-122. doi:10. 1111/j.1467-7652.2005.00162.x

195. Wattebled F, Buleon A, Bouchet B, Ral JP, Lienard L, Delvalle D, Binderup K, Dauvillee D, Ball S, D'Hulst C (2002) Granulebound starch synthase I-a major enzyme involved in the biogenesis of B-crystallites in starch granules. Eur J Biochem 269(15):3810-3820. doi:10.1046/j.1432.1033.2002.03072.x

196. Wattebled F, Dong Y, Dumez S, Delvalle D, Planchot R, Berbezy P, Vyas D, Colonna P, Chatterjee M, Ball S, D'Hulst C (2005) Mutants of Arabidopsis lacking a chloroplastic isoamylase accumulate phytoglycogen and an abnormal form of amylopectin. Plant Physiol 138(1):184-195

197. Wattebled F, Planchot V, Dong Y, Szydlowski N, Pontoire B, Devin A, Ball S, D'Hulst C (2008) Further evidence for the mandatory nature of polysaccharide debranching for the aggregation of semicrystalline starch and for overlapping functions of debranching enzymes in arabidopsis leaves. Plant Physiol 148(3):1309-1323. doi:10.1104/pp.108.129379
198. Whittam MA, Noel TR, Ring SG (1990) Melting behavior of A-type and B-type crystalline starch. Int $\mathrm{J}$ Biol Macromol 12(6):359-362. doi:10.1016/0141-8130(90)90043-a

199. Wischmann B, Blennow A, Madsen F, Jørgensen K, Poulsen P, Bandsholm O (2005) Functional characterisation of potato starch modified by specific in planta alteration of the amylopectin branching and phosphate substitution. Food Hydrocolloids 19(6):1016-1024. doi:10.1016/j.foodhyd.2005.01.002

200. Witt T, Doutch J, Gilbert EP, Gilbert RG (2012) Relations between molecular, crystalline, and lamellar structures of amylopectin. Biomacromolecules 13(12):4273-4282. doi:10.1021/ Bm301586x

201. Wong KS, Kubo A, Jane JL, Harada K, Satoh H, Nakamura Y (2003) Structures and properties of amylopectin and phytoglycogen in the endosperm of sugary-1 mutants of rice. J Cereal Sci 37(2):139-149. doi:10.1006/jcrs 2002.0485

202. Wu AC, Gilbert RG (2010) Molecular weight distributions of starch branches reveal genetic constraints on biosynthesis. Biomacromolecules 11(12):3539-3547. doi:10.1021/Bm1010189

203. Wu AC, Gilbert RG (2013) Program "APCLDFIT". Brisbane. https://sourceforge.net/projects/starchcldfit/?source=directory

204. Wu AC, Morell MK, Gilbert RG (2013) A parameterized model of amylopectin synthesis provides key insights into the synthesis of granular starch. PLoS ONE 8(6):e65768. doi:10.1371/journal. pone. 0065768

205. Yamamori M, Fujita S, Hayakawa K, Matsuki J, Yasui T (2000) Genetic elimination of a starch granule protein, SGP-1, of wheat generates an altered starch with apparent high amylose. Theor Appl Genet 101(1-2):21-29. doi:10.1007/s001220051444

206. Yoo SH, Jane JL (2002) Structural and physical characteristics of waxy and other wheat starches. Carbohydr Polym 49(3):297-305. doi:10.1016/S0144-8617(01)00338-1

207. You SG, Lim ST (2000) Molecular characterization of corn starch using an aqueous HPSEC-MALLS-RI system under various dissolution and analytical conditions. Cereal Chem 77(3):303-308. doi:10.1094/Cchem.77.3.303

208. Yuan RC, Thompson DB, Boyer CD (1993) Fine structure of amylopectin in relation to gelatinization and retrogradation behavior of maize starches from three wx-containing genotypes in two inbred lines. Cereal Chem 70(1):81-89

209. Zeeman SC, Northrop F, Smith AM, ap Rees T (1998) A starchaccumulating mutant of Arabidopsis thaliana deficient in a chloroplastic starch-hydrolysing enzyme. Plant J 15(3):357-365. doi:10.1046/j.1365-313X.1998.00213.x

210. Zeeman SC, Umemoto T, Lue WL, Au-Yeung P, Martin C, Smith AM, Chen J (1998) A mutant of Arabidopsis lacking a chloroplastic isoamylase accumulates both starch and phytoglycogen. Plant Cell 10(10):1699-1711. doi:10.2307/ 3870767

211. Zeeman SC, Kossmann J, Smith AM (2010) Starch: its metabolism, evolution, and biotechnological modification in plants. In: Merchant S, Briggs WR, Ort D (eds) Annual review of plant biology, vol 61. Annual Reviews, Palo Alto, pp 209-234. doi:10.1146/annurev-arplant-042809-112301

212. Zhang XL, Colleoni C, Ratushna V, Sirghle-Colleoni M, James MG, Myers AM (2004) Molecular characterization demonstrates that the Zea mays gene sugary2 codes for the starch synthase isoform SSIIa. Plant Mol Biol 54(6):865-879. doi:10.1007/ s11103-004-0312-1

213. Zhang B, Huang Q, Luo F-x, Fu X, Jiang H, Jane J-1 (2011) Effects of octenylsuccinylation on the structure and properties of high-amylose maize starch. Carbohydr Polym 84(4):1276-1281. doi:10.1016/j.carbpol.2011.01.020 
214. Zhang B, Dhital S, Gidley MJ (2013) Synergistic and antagonistic effects of alpha-amylase and amyloglucosidase on starch digestion. Biomacromolecules 14(6):1945-1954. doi:10.1021/bm400332a

215. Zheng GH, Sosulski FW (1998) Determination of water separation from cooked starch and flour pastes after refrigeration and freeze-thaw. J Food Sci 63(1):134-139. doi:10.1111/j.13652621.1998.tb15693.x
216. Zhu ZP, Hylton CM, Rossner U, Smith AM (1998) Characterization of starch-debranching enzymes in pea embryos. Plant Physiol 118(2):581-590. doi:10.1104/Pp.118.2.581

217. Zhu LJ, Liu QQ, Wilson JD, Gu MH, Shi YC (2011) Digestibility and physicochemical properties of rice (Oryza sativa L.) flours and starches differing in amylose content. Carbohydr Polym 86(4):1751-1759. doi:10.1016/j.carbpol.2011.07.017 